OPEN ACCESS

Edited by:

Roger Chammas,

University of São Paulo, Brazil

Reviewed by: Daniela Taverna,

University of Turin, Italy

Sylvia Le Dévédec,

Leiden University, Netherlands

${ }^{\star}$ Correspondence:

Marko Roblek marko.roblek@ist.ac.at

Daria E. Siekhaus

daria.siekhaus@ist.ac.at

Specialty section:

This article was submitted to Molecular and Cellular Oncology, a section of the journal

Frontiers in Oncology

Received: 15 September 2021

Accepted: 13 January 2022

Published: 08 February 2022

Citation:

Roblek M, Bicher J, van Gogh M, György $A$, Seeböck $R$, Szulc $B$, Damme M, Olczak M, Borsig L and Siekhaus DE (2022) The Solute

Carrier MFSD1 Decreases the

Activation Status of $\beta 1$ Integrin and Thus Tumor Metastasis.

Front. Oncol. 12:777634. doi: 10.3389/fonc.2022.777634

\section{The Solute Carrier MFSD1 Decreases the Activation Status of $\beta 1$ Integrin and Thus Tumor Metastasis}

\author{
Marko Roblek ${ }^{1 *}$, Julia Bicher ${ }^{1}$, Merel van Gogh ${ }^{2}$, Attila György ${ }^{1}$, Rita Seeböck ${ }^{3}$, \\ Bozena Szulc ${ }^{4}$, Markus Damme ${ }^{5}$, Mariusz Olczak ${ }^{4}$, Lubor Borsig ${ }^{2}$ and Daria E. Siekhaus ${ }^{1 *}$ \\ 1 Institute of Science and Technology Austria, Klosterneuburg, Austria, ${ }^{2}$ Institute of Physiology, University of Zurich, \\ Zurich, Switzerland, ${ }^{3}$ Institute of Clinical Pathology, University Hospital St. Polten, St. Polten, Austria, ${ }^{4}$ Laboratory of \\ Biochemistry, Faculty of Biotechnology, University of Wroclaw, Wroclaw, Poland, 5 Institute of Biochemistry, University \\ of Kiel, Kiel, Germany
}

Solute carriers are increasingly recognized as participating in a plethora of pathologies, including cancer. We describe here the involvement of the orphan solute carrier Major Facilitator Superfamily Domain-containing protein 1 (MFSD1) in the regulation of tumor cell migration. Loss of MFSD1 enabled higher levels of metastasis in experimental and spontaneous metastasis mouse models. We identified an increased migratory potential in MFSD1 $1^{-/}$tumor cells which was mediated by increased focal adhesion turnover, reduced stability of mature inactive $\beta 1$ integrin, and the resulting increased integrin activation index. We show that MFSD1 promoted recycling to the cell surface of endocytosed inactive $\beta 1$ integrin and thereby protected $\beta 1$ integrin from proteolytic degradation; this led to dampening of the integrin activation index. Furthermore, downregulation of MFSD1 expression was observed during the early steps of tumorigenesis, and higher MFSD1 expression levels correlate with a better cancer patient prognosis. In sum, we describe a requirement for endolysosomal MFSD1 in efficient $\beta 1$ integrin recycling to suppress tumor cell dissemination.

Keywords: solute carriers (SLC), MFSD1, tumor cell migration, integrin recycling, tumor cell metastasis, $\mathrm{N}$-glycan, transporter, endolysosomal transport

\section{INTRODUCTION}

Solute carriers (SLCs) represent the second most numerous class of integral membrane proteins, encoded by 456 known genes (1), and are outnumbered only by G-protein-coupled receptors. SLCs transport a broad spectrum of different molecules (e.g., sugars, neurotransmitters, vitamins, nucleosides, amino acids) and are therefore essential for the maintenance of homeostasis in mammalian cells, tissues, and organs. About 100 SLC genes are known to cause Mendelian disorders upon mutation (2), while more are expected to have roles in multigenic diseases (1). The interest in studying SLCs is increasing due to their roles in diverse diseases such as neurological disorders, metabolic syndrome, cardiovascular diseases, and cancer (3-6). As of now, only 19 SLC proteins are targeted by drugs (7), and more than $30 \%$ of SLCs remain orphans, with their physiological substrates and functions unknown (1). 
Previously, we have described the essential function of Minerva (Mrva), the fly ortholog of the SLC Major Facilitator Superfamily Domain-containing protein 1 (MFSD1), for the invasive migration of macrophages in the developing Drosophila melanogaster embryo (8). The expression of mouse MFSD1 in macrophages of $\mathrm{mrva}^{-/-}$embryos rescued their invasive cell migration, indicating functional conservation from fly to mouse and a cell-autonomous capacity to control migration by MFSD1 (8). MFSD1 was initially identified as a lysosomal membrane protein (9) and was additionally shown to be required for normal tissue physiology (10), as $\mathrm{MFSD}^{-/-}$mice develop splenomegaly and severe liver disease. The stability of MFSD1 in lysosomes depends on its interaction with Glycosylated Lysosomal Membrane Protein (GLMP) (9, 11). Even these few examples show that MFSD1 is crucial for normal physiology; however, its cellular and molecular functions remain unknown.

Given the capacity of MFSD1 to regulate the invasive migration of macrophages in the fly embryo, we were interested in whether MFSD1 is involved in mammalian tumor cell migration. Drosophila macrophages require integrin for their invasive migration (12). Tumor cell migration depends to a huge extent on integrins, which mediate the anchorage of the cell to the ECM and relay mechanical force to the actin cytoskeleton (13). The deregulation of integrins by diverse mechanisms contributes to a protumorigenic and prometastatic phenotype (13), by affecting expression levels, endocytosis and recycling dynamics $(14,15)$, and glycosylation status $(16,17)$.

Here, we show that MFSD1 in tumor cells restrains metastasis, decreases the rate of migration, and lowers the resistance to mechanical stress and starvation-induced apoptosis by reducing the activation index of $\beta 1$ integrin through the recycling pathway.

\section{MATERIALS AND METHODS}

\section{Cell Culture}

The murine colon carcinoma cell line MC-38 (18), melanoma cell line B16-BL6 (19), and breast cancer cell line 4T1 (ATCC, \#CRL-2539 Manassas, USA) were cultured in DMEM (Thermo Fisher Scientific, 31966-021 Waltham, USA), supplemented with $10 \%$ FCS (Sigma, \#9665) and 1× NEAA (Thermo Fisher Scientific, \#11140-050), and cultivated in incubators set at $37^{\circ} \mathrm{C}$ and $5 \% \mathrm{CO}_{2}$.

MFSD $1^{\mathrm{kd}}$ tumor cells were generated by MISSION lentiviral transduction particles expressing short hairpin RNA (shRNA) from pLKO.1 vector targeting the coding sequence of MFSD1 (Sigma, TRC clone ID TRCN0000338002 and TRCN0000337937 St. Louis, USA) or control shRNA (Sigma, \#SHC216V). Infected cells were selected by puromycin $(2 \mu \mathrm{g} / \mathrm{ml})$ for 5 days.

$\mathrm{MFSD}^{-1-}$ and cognate WT cells were generated from an MC-38 single-cell clone progenitor (gift from $\mathrm{H}$. Clausen lab) and transiently transfected with Lipofectamine 3000 according to the instructions of the manufacturer with gRNA targeting MFSD1
(MMPD0000065783, gRNA sequence: 5'-GGCGGTGTTCC CGTTCATC-3') or GLMP (MMPD0000057180, gRNA sequence: 5'-ACTTGGCCAAGGAGTACGG-3') in line with GFP from the (p04) U6-gRNA : CMV-eCas9-2a-tGFP plasmid (Sigma). One day later, $\mathrm{GFP}^{+}$cells have been single-cell sorted into 96 -well plates by a BD Aria III sorter (BD). Single-cell clones have been expanded and evaluated for efficient knockout by Western blotting. Five single-cell clones for $\mathrm{MFSD}^{-/-}$and WT, respectively, were combined for subsequent experiments. MC-38 $\mathrm{Cosmc}^{-/-}$cells were a gift from H. Clausen.

\section{Recombinant Proteins}

The cloning of MFSD1-eGFP was described previously (8). GLMP-HA was PCR amplified from pcDNA3.1-GLMP-HA (11) with forward primer 5'-GGGGACAAGTTTG TACAAAAAAGCAGGCTTAATGTTTCGCTGTTGG-3' and reverse primer $5^{\prime}$-GGGGACCACTTTGTACAAGAAAGCTG GGTATTAAGCGTAGTCTGGGAC-3'. The PCR product was cloned using Gateway BP Clonase II enzyme mix and Gateway LR Clonase II enzyme mix (Thermo Fisher Scientific) via donor vector pDonR211 into the final doxycycline-inducible expression vector pInducer20 (20) according to the instructions of the manufacturer. QSOX1-StrepTagII was PCR amplified from pCMV3-C-Myc-QSOX1 (Sinobiological, \#MG53456-CM Beijing, China) with forward primer 5'-GGGGACAAGTT TGTACAAAAAAGCAGGCTTAAAGCTTGGTACCATG-3' and reverse primer $5^{\prime}$-GGGGACCACTTTGTACAAGAAAGC TGGGTATTACTTTTCGAACTGCGGGTGGCTCCAA GAGCCTCCACCCCC-3'. The PCR product was processed similar to the GLMP-HA construct.

All constructs were separately packed into lentiviral particles using pdelta8.9 (Addgene, \#2221 Watertown, USA) and pCMVVSV-G (Addgene, \#8454) packaging plamid-transfected Lenti-X 293T cells (TaKaRa, \#632180 Kusatsu, Japan) using Lipofectamine 3000 (Thermo Fisher Scientific). Crude lentiviral supernatant was used for infection of MC-38 cells.

\section{Mice}

All animal experiments were done according to the guidelines of the Swiss Animal Protection Law and approved by the Veterinary Office of the Kanton Zürich. C57BL/6J and BALB/c mice were purchased from The Jackson Laboratory and maintained in individually ventilated cages at $21^{\circ} \mathrm{C}, 55 \%$ humidity, with a photoperiod of $12 \mathrm{~h}$ light and $12 \mathrm{~h}$ dark with standard diet and water available ad libitum.

\section{Western Blot}

Cells were lysed with lysis buffer $(25 \mathrm{mM}$ Tris, $150 \mathrm{mM} \mathrm{NaCl}$, 1 mM EDTA, 1\% Triton X-100), supplemented with Halt Protease and Phosphatase Inhibitor Cocktail (Thermo Fisher Scientific, \#78440) for $20 \mathrm{~min}$ on ice and cleared by centrifugation for $10 \mathrm{~min}$ at $20,000 \times g$. Cell lysates $(10 \mu \mathrm{g})$ were separated on $4 \%-15 \%$ SDS-PAGE gradient gels (Bio-Rad, Hercules, USA) and blotted on Protran 0.45 nitrocellulose membranes (GE Healthcare, Chicago, USA). Membranes were blocked with $1 \times$ Pierce Clear Milk Blocking Buffer (Thermo 
Fisher Scientific, \#37587) for $1 \mathrm{~h}$ at room temperature (RT). Primary antibodies were diluted in $1 \times$ blocking buffer and incubated overnight at $4^{\circ} \mathrm{C}$ and included the following: antiMFSD1 (10), anti- $\beta$ tubulin (Cell Signaling Technology, \#2146S Danvers, USA), anti-GLMP (10), anti- $\beta 1$ integrin (Thermo Fisher Scientific, \#PA5-78028), anti-GAPDH (Abcam, \#ab181603 Cambridge, UK), anti-T antigen [clone 3C9, gift from H. Clausen (21)], anti-QSOX1 [gift from D. Fass (22)], anti-LAMP1 (clone 1D4B, BioLegend, \#121601 San Diego, USA), anti-cleaved caspase 3 (Cell Signaling Technology, \#9661S), and streptavidin-HRP (Thermo Fisher Scientific, $\#$ S911). Subsequently, membranes were washed $3 \times$ with TBS-T and incubated with either goat anti-mouse IgG $(\mathrm{H}+\mathrm{L})-\mathrm{HRP}$ conjugate (Bio-Rad, \#1721011) or goat anti-rabbit IgG (H+L)HRP conjugate (Bio-Rad, \#1706515) secondary antibody. After $3 \times$ washing with TBS-T, the membrane was incubated with SuperSignal West Femto Maximum Sensitivity Substrate (Thermo Fisher Scientific, \#34096) and the chemoluminescence signals were detected with the ChemiDoc MP Gel Imaging System (Bio-Rad). Densitometric analysis of Western blot bands was performed with ImageJ.

\section{Immunofluorescence}

The expression of MFSD1-eGFP was induced by $100 \mathrm{ng} / \mu \mathrm{l}$ doxycycline for $24 \mathrm{~h}$ prior to cell fixation. Cells were seeded on Nunc Lab-Tek Chamber Slides (Thermo Fisher Scientific, \#154534) and fixed with 4\% FA/PBS (Thermo Fisher Scientific, \#28906) for $10 \mathrm{~min}$ at RT. Samples were washed $3 \times$ with PBS and blocked/permeabilized with $1 \%$ BSA/0.1\% Triton X-100 in PBS for $1 \mathrm{~h}$ at RT. Samples were then stained with antibodies for $2 \mathrm{~h}$ at RT, which included anti-GFP (clone 5G4, from E. Ogris), antiHA-tag (clone 3F10, Sigma, \#11867432001), anti-giantin (BioLegend, \#19243), LysoTracker Red DND-99 (Thermo Fisher Scientific, \#L7528), anti-Rab5A (Cell Signaling Technologies, \#46449), anti-Rab7 (Cell Signaling Technologies, \#9367), anti-Rab11 (Cell Signaling Technologies, \#5589), anti-mTOR (Cell Signaling Technologies, \#2983S), and antipaxillin (Abcam, \#ab32084). Samples were washed $3 \times$ with PBS and incubated with secondary antibodies, which included anti-mouse Alexa Fluor 488 (Thermo Fisher Scientific, \#A11001), anti-rabbit Alexa Fluor 555 (Thermo Fisher Scientific, \#A31572), anti-rabbit Alexa Fluor 488 (Thermo Fisher Scientific, \#A11008), anti-rabbit Alexa Fluor 633 (Thermo Fisher Scientific, \#A21070), and anti-rat Alexa Fluor 546 (Thermo Fisher Scientific, \#A11081). Samples were washed and counterstained with DAPI for $10 \mathrm{~min}$ and subsequently mounted in ProLong Diamond Antifade Mountant (Thermo Fisher Scientific, \#P36970). Pictures were taken on a Zeiss LSM880 inv. Fast Airyscan or Zeiss LSM800 inv. Airyscan confocal microscope with a Plan-Apochromat $\times 40 / \mathrm{NA} 1.3$ OIL, or Plan-Apochromat $\times 40 / 1.2$ water objective, respectively. Colocalization (Pearson's $R$ value with the Coloc 2 tool), fluorescence intensity, and particle size were analyzed by ImageJ. In detail, lysosomes were stained with LysoTracker Red DND-99 (Thermo Fisher Scientific, \#L7528) and z-stacks $(0.5 \mu \mathrm{m})$ were recorded as described above. Individual lysosomes were analyzed for their roundness (ratio of width/length), which was unaffected by MFSD1 and resembled an ellipsoid shape (data not shown). The area ( pixel $^{2}$ ) of individual lysosomes was determined by the following formula: Area $_{\text {ellipse }}=($ width $/ 2) *$ (length $/ 2$ ) $* \pi$. The number of lysosomes was determined by manual counting of LysoTracker Red DND- $99^{+}$vesicles, where the border of cells was determined according to the brightfield image.

Focal adhesion parameters were analyzed as follows: cells were stained with anti-paxillin (Abcam, \#ab32084) and antirabbit Alexa Fluor 555 (Thermo Fisher Scientific, \#A31572) and recorded as described above. Focal adhesion size, fluorescence intensity, and focal adhesions per image were analyzed by the Analyze Particle tool of ImageJ, with the same adjustments (brightness, contrast, threshold) for each image. The number of automatically counted adhesion sites was divided by the number of $\mathrm{DAPI}^{+}$nuclei in each image to give focal adhesions per cell.

\section{Flow Cytometry}

Twenty-four hours before staining, cells were incubated with or without $10 \mu \mathrm{g} / \mathrm{ml}$ 9EG7 antibody (BD Biosciences, \#553715 Franklin Lakes, USA) or $20 \mu \mathrm{g} / \mathrm{ml}$ primaquine (Sigma, \#160393). Cells were stained in $100 \mu \mathrm{l}$ FACS buffer (2\% FCS/ $10 \mathrm{mM}$ EDTA in PBS) with the following antibodies and lectins: PNA-FITC, WGA-FITC, and LPA-FITC (were from EY Laboratories) (FITC-labeled lectin kit \#2); anti- $\beta 1$ integrin (clone HMb1-1, BioLegend, \#102202); anti- $\beta 1$ integrinAPC (clone HMb1-1, BioLegend, \#102215); anti-active $\beta 1$ integrin (clone 9EG7, BD Biosciences, \#553715); 7-AAD (Thermo Fisher Scientific, \#A1310); and AnnexinV-PE (BioLegend, \#640908). Cells were washed once with $1 \mathrm{ml}$ buffer and, if applicable, stained again in $100 \mu \mathrm{l}$ buffer with the anti-rat Alexa Fluor 488 (Thermo Fisher Scientific, \#A11006) secondary antibody, followed by one wash with 1 $\mathrm{ml}$ buffer. Cells were resuspended in $300 \mu \mathrm{l}$ buffer and data were acquired on a BD FACS Canto II Analyzer (BD Biosciences) and analyzed by FlowJo software (TreeStar Inc., Ashland, USA).

\section{Wound Closing Assay}

A total of 60,000 cells were seeded per chamber on CultureInsert 2 Well in $\mu$-Dish $35 \mathrm{~mm}$ (ibidi GmbH, Gräfelfing, Germany) $24 \mathrm{~h}$ before treatment with the cytostatic mitomycin C $(10 \mu \mathrm{g} / \mathrm{ml}$, Sigma, \#M4287) for $3.5 \mathrm{~h}$ in normal medium, followed by removal of the insert, and one wash step with cell culture medium. For the start of the migration, fresh cell culture medium was added with or without $10 \mu \mathrm{g} / \mathrm{ml}$ 9EG7 antibody (BD Biosciences, \#553715). The progress of migration was recorded every minute with temperature- and $\mathrm{CO}_{2}$ controlled Leica DM IL LED microscopes with Leica HI PLAN I $\times 10 / 0.22$ air objectives. Videos were analyzed with Wound Healing FastTrack AI Image Analysis (ibidi GmbH), or the respective images at indicated time points are shown. The wound size at the start of migration was equalized to the smallest wound size at the particular experiment to correct for different wound sizes. 


\section{Experimental Metastasis}

A total of 300,000 MC-38 or 150,000 B16-BL6 cells in $100 \mu \mathrm{l} \mathrm{HBSS}$ (Sigma, \#H9394) were injected into the tail vein of C57BL/6J mice. Four or 2 weeks after intravenous injection of tumor cells, respectively, lungs were perfused with PBS and the number of macroscopic metastatic foci was counted.

To address the effect of the increased $\beta 1$ integrin activation index on pulmonary metastasis initiation, MC-38 WT cells were preincubated with $10 \mu \mathrm{g} / \mathrm{ml}$ 9EG7 antibody (BD Biosciences, \#553715) for $24 \mathrm{~h}$ prior to injection into the tail vein of C57BL/6J mice and analyzed as described above.

\section{Spontaneous Metastasis}

We injected $20 \mu \mathrm{l}$ of a one to one mixture of Matrigel (Sigma, \#CLS356252) and 100,000 4T1 cells in HBSS (Sigma, \#H9394) into the mammary fat pad of female BALB/c mice. Two weeks after tumor cell injection, the primary tumor was resected, and 2 weeks later ( 4 weeks after the initial tumor cell injection), the lungs were perfused with PBS and the number of macroscopic metastatic foci visible to the eye in the lungs was counted manually. During perfusion, the lung becomes white since all the red blood cells are washed out. In the metastatic foci, the red blood cells are not washed out as efficiently due to the semifunctional vasculature of metastases. The metastatic cells themselves are also light brown compared with the white untransformed lung tissue. Thus, what remains visible after perfusion are somewhat elevated reddish-brown hemispherical hubs. Each such hub was individually counted as a metastatic focus.

\section{Hematoxylin and Eosin Staining}

Lung tissue paraffin sections $(2 \mu \mathrm{m})$ from the spontaneous metastasis experiments were stained with hematoxylin/eosin according to established protocols and imaged with an Olympus BX53 microscope using a UPlanSApo $\times 4 / 0.16 \mathrm{NA}$ (Olympus, Shinjuku, Japan) objective.

\section{Matrigel Invasion Assay}

A total of 100,000 MC-38 cells were seeded in $500 \mu \mathrm{l}$ DMEM + $1 \%$ FCS atop of Corning BioCoat Matrigel Invasion Chambers with $8 \mu \mathrm{m}$ PET Membrane (Corning, \#354480 Corning, USA), and chemotaxis was induced by the presence of DMEM $+10 \%$ FCS in the bottom chamber. Invasive migration was stopped after $24 \mathrm{~h}$ and cells reaching the bottom side of the PET membrane were fixed with methanol and stained with Giemsa's solution. PET membranes were cut out and mounted in ProLong Diamond Antifade Mountant (Thermo Fisher Scientific, \#P36970) on objective slides. Per membrane, three to four pictures at a random location were taken for the determination of the efficiency of invasive migration with a Leica DMI 6000B Microscope with a Leica N PLAN ×10/0.25 air objective.

\section{Proliferation Ratio Determination}

MC-38 WT-eGFP and MC-38 $\mathrm{MFSD}^{-1-}$-mCherry cells were seeded together in six-well plates and their ratio was determined for the 0 -h time point. This ratio was observed also after 24,48 ,
72, and $96 \mathrm{~h}$ after seeding and normalized to the 0 -h time point ratio. No change of ratio (ratio close to the value 1) indicates equal proliferation.

\section{Spreading Assay}

The experiment was done as described in (23). Briefly, cells were starved of serum for $1 \mathrm{~h}$ prior to $2 \mathrm{~min}$ of incubation with trypsin-EDTA (Thermo Fisher Scientific, \#25300-054), quenched with serum-free medium and centrifuged for $5 \mathrm{~min}$ at $300 \times g$. Cells were resuspended in a cell density of 200,000 cells $/ \mathrm{ml}$ in serum-free medium and incubated in the conical tube in the incubator. Meanwhile, $50 \mu \mathrm{l}$ of serum-free medium was added to the wells of a 96-well plate, which have or have not been previously coated with $10 \mu \mathrm{g} / \mathrm{ml}$ fibronectin (Sigma, \#F2006) for $30 \mathrm{~min}$, and equilibrated in the incubator. Then, $50 \mu \mathrm{l}$ of the cell suspension was added and incubated for 20 and $40 \mathrm{~min}$ followed by direct addition of $20 \mu \mathrm{l} 25 \%$ glutaraldehyde (Sigma, \#G5882). Cells were fixed for $30 \mathrm{~min}$ at RT and then the fixed cells were washed and stored in PBS. Three random pictures at each replicate (individual 96-well) were taken by a Leica DM IL LED microscope with Leica HI PLAN I $\times 10 / 0.22$ air objective. Spread cells were manually counted.

\section{CORA Analysis}

To analyze O-glycans, the procedure reported by Kudelka et al. (24) was adopted, as reported recently $(25,26)$. In brief, the cells were incubated in medium containing $5 \%$ serum with $50 \mu \mathrm{M}$ peracetylated $\mathrm{O}$-glycan precursor $\left(\mathrm{Ac}_{3} \mathrm{GalNAcBn}\right)$ and grown for $72 \mathrm{~h}$. Then, the conditioned media were collected and centrifuged $(1,000 \times g, 5 \mathrm{~min})$, and the supernatants were subjected to glycan extraction procedure. Next, isolated Oglycans were permethylated and subsequently analyzed using MALDI-TOF mass spectrometry.

\section{N-glycan Analysis}

Cells from $10-\mathrm{cm}$ plates were lysed using the CelLytic M reagent (Sigma-Aldrich), and the protein concentration in obtained lysates was adjusted to $2 \mathrm{mg} / \mathrm{ml}$. Cellular proteins were precipitated by the addition of one volume of iced $100 \%$ acetone and incubated at $-20^{\circ} \mathrm{C}$ overnight. Samples were centrifuged $(14,000 \times g, 15 \mathrm{~min}, \mathrm{RT})$ and the pellet containing precipitated proteins was air dried. Precipitated proteins were resuspended in $150 \mu \mathrm{l}$ of Glycoprotein Denaturing Buffer [New England Biolabs (NEB), Ipswich, USA] and incubated at $100^{\circ} \mathrm{C}$ for $10 \mathrm{~min}$. Afterwards, the following PNGase F reaction mixture was assembled: cellular protein sample $(100 \mu \mathrm{l}), 10 \% \mathrm{NP}-40(20$ $\mu l, N E B)$, G7 Reaction buffer $(20 \mu \mathrm{l}, \mathrm{NEB})$, deionized water (60 $\mu \mathrm{l})$, and PNGase F (4.5 $\mu \mathrm{l}, 150 \mathrm{U})$. The reaction mixture was incubated at $37^{\circ} \mathrm{C}$ for $4 \mathrm{~h}$; afterwards, another $3 \mu \mathrm{l}$ of PNGase $\mathrm{F}$ was added and incubated for a total of $24 \mathrm{~h}$ at $37^{\circ} \mathrm{C}$. Purification of $\mathrm{N}$-glycans from the reaction mixture was done on the Supelclean $^{\mathrm{TM}}$ ENVI-Carb ${ }^{\mathrm{TM}}$ SPE graphitized carbon tubes (Sigma-Aldrich). Prior to purification, the columns were treated sequentially with $1 \mathrm{M} \mathrm{NaOH}(3 \mathrm{ml}), \mathrm{H}_{2} \mathrm{O}(2 \times 3 \mathrm{ml})$, $30 \%$ acetic acid $(3 \mathrm{ml})$, and $\mathrm{H}_{2} \mathrm{O}(2 \times 3 \mathrm{ml})$. Afterwards, $3 \mathrm{ml}$ of $50 \%$ acetonitrile with $0.05 \%$ TFA was added, followed by $6 \mathrm{ml}$ of 
$3 \%$ acetonitrile with $0.05 \%$ TFA. Glycan samples were centrifuged and the supernatant was applied to the columns. The columns were then washed first with water $(3 \mathrm{ml})$, then with $3 \%$ acetonitrile and $0.05 \%$ TFA solution. Glycans were eluted with $50 \%$ acetonitrile and $0.05 \%$ TFA solution $(4 \times 0.5 \mathrm{ml})$. The obtained samples were lyophilized overnight in a vacuum concentrator.

Released N-glycans were fluorescently labeled on the nonreducing end with 2-aminobenzamide (2-AB) and separated on GlycoSepN column (Prozyme, Hayward, USA) connected to the HPLC system, as previously described (27).

\section{MALDI-TOF Analysis of N- and O-glycans}

MALDI-TOF-MS experiments were performed on an AximaPerformance TOF spectrometer (Shimadzu Biotech, Kyoto, Japan), equipped with a nitrogen laser $(337 \mathrm{~nm})$. The pulsed extraction ion source accelerated the ions to a kinetic energy of $20 \mathrm{keV}$. Data were obtained in a positive-ion linear mode. The calibration of the linear mode analysis was done using polyethylene glycol in mass range up to 5,000 $\mathrm{Da}$. The accuracy of the product ion calibration was approximately 1.5 $\mathrm{Da}$. The mass calibration was conducted based on the average masses. The samples were dissolved in $20 \%$ acetonitrile in water. As a matrix, 2,5-dihydroxybenzoic acid $(20 \mathrm{mg} / \mathrm{ml})$ dissolved in $20 \mathrm{mM}$ sodium acetate in $20 \%$ acetonitrile in water was used. The sample and the matrix were combined at a 1:1 ratio. The resulting solution $(1 \mu \mathrm{l})$ was spotted on a 384-well MALDITOF plate, followed by evaporation of the solvent at ambient temperature without any assistance. Each mass spectrum was accumulated from at least 200 laser shots and processed by Biotech Launchpad ver. 2.9.1 program (Shimadzu).

\section{Detachment Experiment}

Cells were grown on uncoated or fibronectin-coated $\mu$-Slide 8-well chambers (ibidi, \#80826 Abingdon, UK) to $80 \%-90 \%$ confluency, washed with PBS, and detached with $10 \mathrm{mM}$ EDTA in PBS, $230 \mu \mathrm{M}$ RGDS peptide (Tocris, \#3498 Abingdon, UK) in PBS, or $0.05 \%$ trypsin/EDTA (Thermo Fisher Scientific, \#25300-054). Detachment was observed under a microscope, and within a few minutes (2-4 min) slides were rocked and the detaching solution was sucked off, and immediately the remaining bound cells were fixed with $4 \% \mathrm{FA} /$ PBS for 15 min. Fixed cells were washed and stained with crystal violet for $30 \mathrm{~min}$ at RT, washed again, and stored in PBS. Three to four pictures at random locations of each chamber were taken with a Leica DM IL LED microscope with a Leica HI PLAN I ×10/0.22 air objective. Area covered by still adherent cells was determined with ImageJ.

\section{QSOX1 Activity Assay}

QSOX1-STII was purified from the supernatant of MC-38 WT or $\mathrm{MFSD}^{-1-}$ cells and $0.5 \mu \mathrm{g}$ was used in a total reaction volume of $150 \mu \mathrm{l}$ in 96-well plates. The final reaction mixture contained 1 $\mathrm{mM}$ homovanillic acid (Sigma, \#1252), $1.4 \mu \mathrm{M}$ horseradish peroxidase (Sigma, \#P6782), $133 \mu \mathrm{M}$ DTT, $50 \mathrm{~mm} \mathrm{~K} \mathrm{HPO}_{4}$ ( $\mathrm{pH} 7.5$ ), and $1 \mathrm{mM}$ EDTA. Purified QSOX1-STII was added to the wells just prior to the start of the measurements.
Dimerization of homovanillic acid was recorded every $30 \mathrm{~s}$ for 20 min with a BioTek Synergy H1 plate reader (BioTek, Winooski, USA) spectrophotometer with an $\mathrm{Ex}=320 \mathrm{~nm}$ and $\mathrm{Em}=420 \mathrm{~nm}$.

\section{RNA Isolation and qPCR}

RNA was isolated with the RNeasy Mini Kit (Qiagen, \#74104 Hilden, Germany) and cDNA produced with the Omniscript RT Kit (Qiagen, \#205111) with oligo dT primers. qPCR reactions were assembled according to the Takyon No ROX SYBR $2 \mathrm{x}$ MasterMix blue dTTP (Eurogentec, \#UF-NSMT-B0701 Seraing, Belgium) qPCR kit. qPCR was performed on a LightCycler 480 (Roche, Basel, Switzerland) and data were analyzed with the LightCycler 480 software. $2^{-\Delta \Delta c t}$ (compared with WT) was displayed. The following primers were used: GAPDH-fw, C C CA GCA A G GA C A C T GA GCAA; GA P DH - rev, GTGGGTGCAGCGAACTTTATTGATG; ITGb 1 - fw, G A A A G C A G G G A G A A G T T G G C; I T G b 1 - r e v, TGATGTCGGGACCAGTAGGA.

\section{Immunoprecipitation of $\beta 1$ Integrin Including the Glycosidase Experiment}

$\beta 1$ Integrin was immunoprecipitated with anti- $\beta 1$ integrin (clone HMb1-1, BioLegend, \#102202) or anti-active $\beta 1$ integrin (clone 9EG7, BD Biosciences, \#553715) from cell lysates for $30 \mathrm{~min}$ on ice, followed by pull-down with Dynabeads Protein G (Thermo Fisher Scientific, \#10003D) for $1 \mathrm{~h}$ on ice. Beads were washed $3 \times$ with PBS and either boiled in $1 \times$ Laemmli Sample Buffer (BioRad, \#1610747) or treated with EndoH (New England BioLabs, \#P0702S) or PNGaseF (New England BioLabs, \#P0704S) according to the instructions of the manufacturer.

Cell-surface $\beta 1$ integrin was immunoprecipitated with incubation of intact cells with the aforementioned antibodies in FACS buffer for $30 \mathrm{~min}$ on ice, washed once with PBS, and lysed with $1 \%$ Triton X-100 in PBS. The cell lysate was cleared by centrifugation and the protocol continued as described in the previous paragraph.

\section{Starvation Experiment}

Cells were grown until they reached $80 \%-90 \%$ confluency. The cell culture medium was removed, and cells were washed twice with PBS and were incubated for $48 \mathrm{~h}$ in DMEM (Thermo Fisher Scientific, 31966-021) with or without $10 \mu \mathrm{g} / \mathrm{ml}$ 9EG7 antibody (BD Biosciences, \#553715) or for $24 \mathrm{~h}$ with or without $0.16 \mu \mathrm{M}$ bafilomycin A1 (Sigma, \#SML1661). Cells were lysed with lysis buffer and processed for analysis by Western blotting.

\section{Mechanical Stress Resistance Experiment}

Cells were grown on six-well plates until $80 \%-90 \%$ confluency in the presence or absence of $10 \mu \mathrm{g} / \mathrm{ml}$ 9EG7 antibody (BD Biosciences, \#553715) for $24 \mathrm{~h}$ and scraped off manually with a rubber Corning Cell Lifter (Corning, \#3008). Cells were stained with 7-AAD (Thermo Fisher Scientific, \#A1310) and AnnexinVPE (BioLegend, \#640908), and data were acquired by flow cytometry with a BD FACS Canto II Analyzer (BD Biosciences) and analyzed by FlowJo software (TreeStar Inc.). 


\section{Cell-Surface Biotinylation Experiment}

Cells were grown on six-well plates until $80 \%-90 \%$ confluency and cell-surface proteins were biotinylated with EZ-Link NHSPEG4-Biotin (Thermo Fisher Scientific, \#21330) at $0.5 \mathrm{mg} / \mathrm{ml}$ in HBSS (Thermo Fisher Scientific, \#14170112) for $45 \mathrm{~min}$ at $4^{\circ} \mathrm{C}$. Biotin was washed off with PBS and cells were either lysed (0-h time point) or incubated with normal cell culture medium for $12 \mathrm{~h}$ and then lysed (12-h time point) with cell lysis buffer. Cell lysates were cleared by centrifugation and $\beta 1$ integrin was immunoprecipitated with anti- $\beta 1$ integrin (clone HMb1-1, BioLegend, \#102202) and Dynabeads Protein G (Thermo Fisher Scientific, \#10003D) for $15 \mathrm{~min}$ at RT. Beads were washed twice with PBS and then boiled in 1× Laemmli Sample Buffer (Bio-Rad, \#1610747). Samples were subjected to Western blot analysis.

\section{Degradation of $\beta 1$ Integrin}

Cells were grown on six-well plates until 80\%-90\% confluency. Cells were then treated with $5 \mu \mathrm{g} / \mathrm{ml}$ brefeldin A (Sigma, \#B7651) for $12 \mathrm{~h}$ in normal cell culture medium and then lysed. Cell lysates were analyzed by Western blot.

\section{Statistical Analysis}

Statistical analysis was performed with GraphPad Prism software (version 9.2.0). Data are presented as mean \pm SEM and were analyzed depending on the number of groups by two-way ANOVA with the Sidak's multiple comparison test or with the Mann-Whitney test.

\section{RESULTS}

\section{MFSD1 Slows Tumor Cell Migration and Metastasis Initiation}

We aimed to study the effect of MFSD1 on tumor cell migration. We prepared a murine colon carcinoma cell line MC-38 MFSD $^{\mathrm{kd}}$ stably expressing a shRNA which reduces MFSD1 expression by $75 \%$ compared with the levels in corresponding control cells expressing an nt-shRNA (Figure 1A). We achieved similar levels of shRNA knockdown of MFSD1 in two other murine tumor cell lines, 4T1 breast cancer and B16-BL6 melanoma (Supplementary Figure 1A). MC-38 MFSD $1^{\mathrm{kd}}$ cells migrated faster in a wound closing assay compared with cognate control cells (Figures 1B, C). This increased migration was also observed upon MFSD1 knockdown in 4T1 and B16-BL6 tumor cell lines (Supplementary Figure 1B), supporting a role for MFSD1 in tumor cell migration across tumor cell types. We also observed increased invasive migration by MC- 38 MFSD $1^{\mathrm{kd}}$ cells in a Matrigel invasion assay (Supplementary Figure 1C). To eliminate the residual MFSD1 expression seen in the MFSD $1^{\mathrm{kd}}$ condition, we generated MC- $38 \mathrm{MFSD1}^{-1-}$ cells by CRISPRCas9-mediated gene editing (Supplementary Figure 1D). $\mathrm{MFSD1}^{-/-}$cells closed the wound faster in the wound closing assays when compared with the respective WT cells (Figures 1D, E) confirming the MFSD1 ${ }^{\mathrm{kd}}$ data. The proliferation of cells was unaffected by the presence of MFSD1 (Supplementary Figure 1E), indicating that the difference in migration and metastatic foci formation is independent of an effect on proliferation. Previously, GLMP has been identified as a crucial interaction partner of MFSD1 (10); thus, we additionally prepared MC-38 $\mathrm{GLMP}^{-1-}$ cells with the CRISPR-Cas9 method. Western blotting with respective antibodies confirmed the elimination of the endogenous protein in the MFSD $1^{-/}$and $\mathrm{GLMP}^{-/-}$lines, and we could confirm that the stability of the two proteins is mutually dependent (Supplementary Figure 1D). $\mathrm{GLMP}^{-/-}$cells also migrated and closed the wound faster than the corresponding WT cells (Supplementary Figures 1F, G), phenocopying the $\mathrm{MFSD1}^{-/-}$cells. In sum, these experiments clearly demonstrate that MFSD1 suppresses the in vitro migration of multiple tumor cell types.

\section{MFSD1 Suppresses Lung Metastases In Vivo}

Next, we sought to expand our in vitro tumor migration assays into in vivo metastasis. We detected increased number of lung metastases in mice intravenously (i.v.) injected with MFSD $1^{\text {kd }}$ tumor cells compared with the control for both MC-38 (Figure 1F) and B16-BL6 (Supplementary Figure 1H) cells. To better mimic the natural process of metastatic initiation, we orthotopically injected 4T1 control (nt-shRNA) or 4T1 MFSD ${ }^{1 \mathrm{kd}}$ cells into the mammary fat pad. Supporting a role of MFSD1 during the entire metastatic cascade starting at the primary tumor, we observed an increased number of pulmonary metastases in mice injected with $4 \mathrm{~T} 1 \mathrm{MFSD} 1^{\mathrm{kd}}$ compared with control cells (Figure 1G). Thus, these experiments support the conclusion that for multiple types of murine cancer cell lines, MFSD1 suppresses metastasis in vivo.

\section{MFSD1 Localizes to the Golgi and to the Endolysosomal System}

To gain insight into the possible functions of MFSD1, we examined its subcellular location in tumor cells. Previously, we had shown that it localizes predominantly to the Golgi apparatus in tumor cell lines but is found in both the Golgi apparatus and the endolysosomal system in fly macrophages (8). To enable a deeper analysis of its localization, we used doxycycline-inducible expression of MFSD1-eGFP (Supplementary Figure 2A), as constitutive expression of MFSD1 was toxic to cells (data not shown). In tumor cells, the strongest MFSD1 staining colocalized with its accessory subunit GLMP in the Golgi apparatus (Figure 2A). However, a careful scrutiny of MFSD1 stainings revealed an additional weaker vesicle-like staining pattern. This MFSD1-eGFP ${ }^{+}$pattern co-localized with acidic compartments stained in live conditions by the LysoTracker dye, indicating the presence of MFSD1 within the endolysosomal system (Figures 2A, B). To further delimit MFSD1 to specific endosomal vesicles, we stained cells with a panel of vesiclespecific antibodies, including the early endosomal marker Rab5, late endosomal marker Rab7, recycling endosomal marker Rab11, and lysosomal marker mTOR (Supplementary 

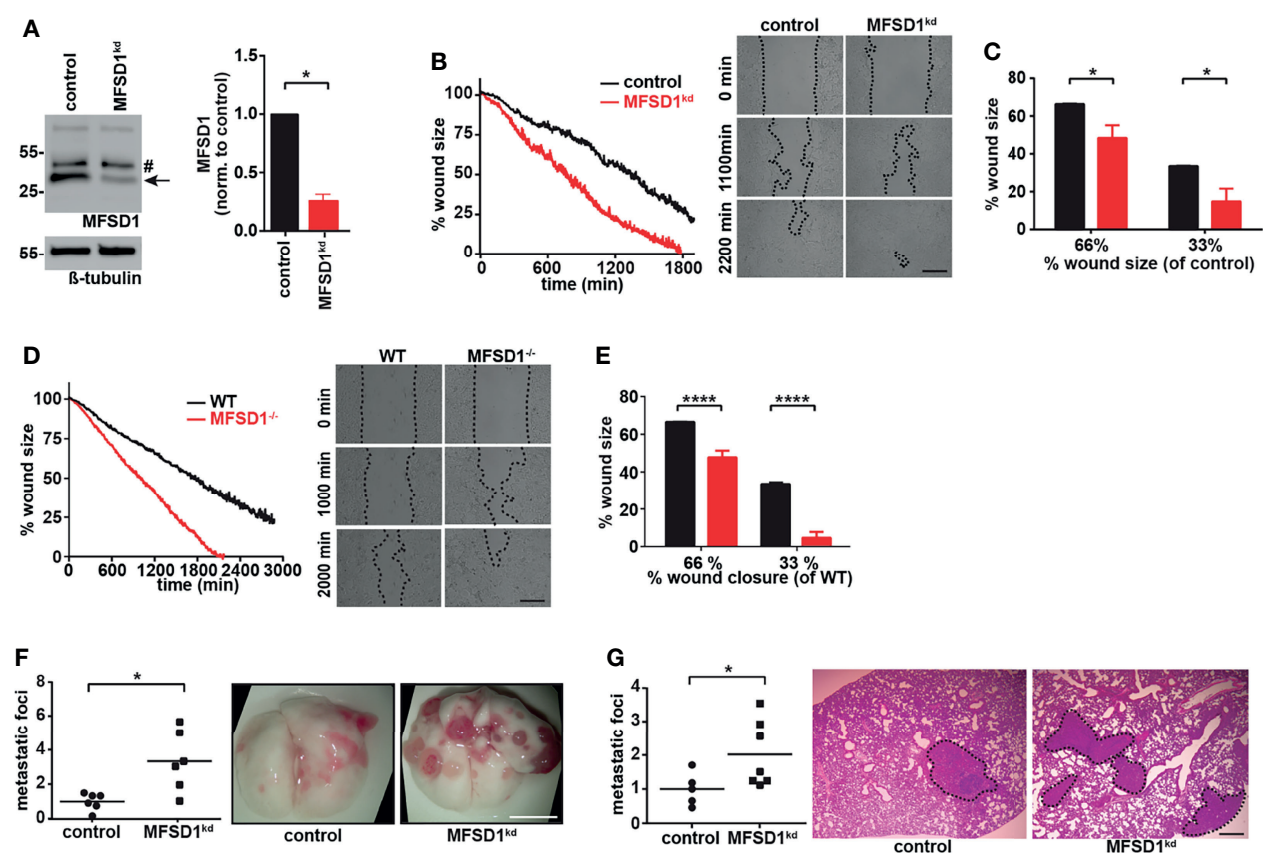

FIGURE 1 | Major Facilitator Superfamily Domain-containing protein 1 (MFSD1) suppresses tumor cell migration. (A) Western blot of MC-38 cells expressing shRNA non-target (control) or shRNA MFSD1 (MFSD1 ${ }^{\mathrm{kd}}$ ) (left panel). Quantification of MFSD1 protein levels by densitometry (right panel) $(n=4)$. Arrow indicates MFSD1 band; \# indicates unspecific band. (B) Wound closing assay of MC-38 control and MFSD1 ${ }^{\mathrm{kd}}$ cells. Graph depicting the continuous shrinking of the wound (left panel) with pictures at defined time points (right panel). Data from one representative experiment are shown. Bar $=0.2 \mathrm{~mm}$. (C) Analysis of the wound closing assay of MC38 control and MFSD1 ${ }^{\mathrm{kd}}$ cells $(n=4)$. The \% wound size remaining for MFSD ${ }^{\mathrm{kd}}$ cells when control cells have moved to shrink the wound to either $66 \%$ or $33 \%$ of the original size is depicted. (D) Wound closing assay of MC-38 WT and MFSD1 $1^{-/}$cells. Graph depicting the continuous shrinking of the wound (left panel) with pictures at defined time points (right panel). Data from one representative experiment are shown. Bar $=0.2 \mathrm{~mm}$. (E) Analysis of wound closing assay of MC-38 WT and MFSD1 $1^{-/}$cells $(n=5)$. The $\%$ wound size remaining for MFSD1 ${ }^{-/}$cells when control cells have moved to shrink the wound to either $66 \%$ or $33 \%$ of the original size is depicted. (F) Experimental metastasis with MC-38 control and MFSD $1^{\mathrm{kd}}$ cells. Representative images of the lungs are shown on the right. Scale bar: $0.5 \mathrm{~cm}$. (G) Spontaneous metastases of $4 \mathrm{~T} 1$ control and MFSD ${ }^{\mathrm{kd}}$ cells. Representative images of H\&E-stained lungs are shown on the right. Metastatic tissue is encircled and highlighted with a black dashed line. Scale bar: $0.5 \mathrm{~mm}$. For $(\mathbf{F}, \mathbf{G})$, the relative number (normalized to the mean seen in the control) of macroscopic metastatic foci per lung is shown. Each dot in the graph indicates the normalized number of foci observed upon visual inspection in the lungs from one mouse. In (F), $n=6$ mice for both genotypes. In (G), control: $n=5$ mice; MFSD1 ${ }^{\mathrm{kd}}: n=7$ mice. ${ }^{\star} p<0.05 ;{ }^{\star \star \star \star} p<0.0001$.

Figure 2B). MFSD1-eGFP co-localized most strongly with the late endosomal marker Rab7, followed by the early endosomal marker Rab5, the lysosomal marker mTOR, and the recycling endosomal marker Rab11 (Supplementary Figure 2B).

To assess if the localization pattern of MFSD1 is conserved across different cell types, we examined MFSD1-eGFP expressed in NIH-3T3 fibroblasts. Interestingly, here we found MFSD1 positioned exclusively in the endolysosomal compartment (Supplementary Figure 2C), localized with the late endosomal marker Rab7 and lysosomal marker mTOR, followed by colocalization with the recycling and early endosomal markers Rab11 and Rab5, respectively (Figure 2C and Supplementary Figures 2C, D). The same additional weaker vesicle-like staining pattern seen with MFSD1-eGFP in MC-38 cells was also observed for GLMP, indicating that they co-localize in the Golgi apparatus as well as in the endolysosomal compartment (Figure 2A and Supplementary Figure 2E). We hypothesize that the Golgi localization of MFSD1-eGFP in tumor cells might be due to tumor cell-specific retention in the Golgi apparatus. The presence of MFSD1 in tumors in the Golgi apparatus and the endolysosomal system indicate two different axes through which it could affect biological processes, which we addressed in our subsequent experiments.

\section{MFSD1 Does not Influence Glycosylation}

Cell-surface glycans, added to proteins in the Golgi apparatus, play important roles during cell migration and metastatic spread (28, 29). Previously, we have described an effect of Minerva, the fly ortholog of MFSD1, on the O-glycome of D. melanogaster embryos (8). We tested the functionality of the O-glycosylation machinery after the initial GalNAc addition in our tumor cells by the Cellular O-Glycome Reporter/Amplification (CORA) approach (24). This assay uses a modified GalNAc- $\alpha$-benzyl which cannot be covalently attached to proteins, but which is secreted to the medium upon extension with other sugars by the action of glycosyl-transferases. The overall secreted O-glycome of MC-38 WT and MFSD1 ${ }^{-/-}$cells consisted predominantly of sialyland disialyl-T antigen, which were present in the same amounts in both cell types (Supplementary Figure 3A), indicating that the enzymes required for $\mathrm{O}$-glycan generation subsequent to initial 


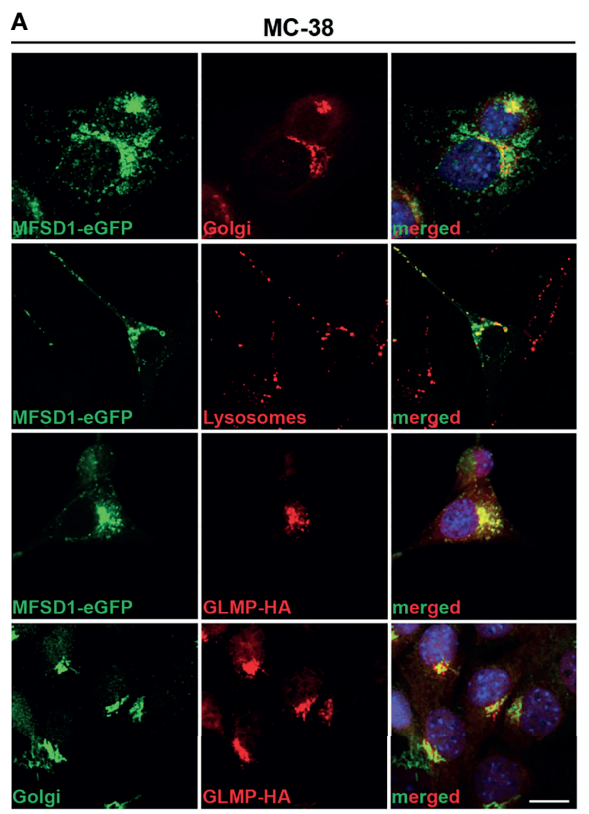

B
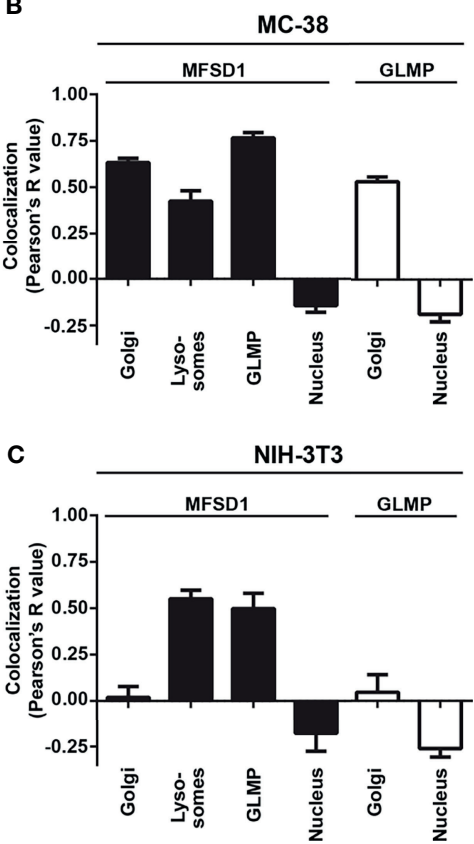

FIGURE 2 | MFSD1-eGFP localizes to the Golgi apparatus and endolysosomal system in tumor cells. (A) Immunofluorescence pictures of MC-38 MFSD1-eGFP cells with the indicated markers. Golgi compartment was stained with an antibody against giantin and lysosomes were stained with LysoTracker Red DND-99. Nuclei were counterstained with DAPI and are highlighted in blue. Bar $=10 \mu \mathrm{m}$. (B) Co-localization analysis of MFSD1-eGFP and GLMP-HA with indicated subcellular markers in MC-38 tumor cells $(n \geq 13)$. (C) Co-localization analysis of MFSD1-eGFP and GLMP-HA with indicated subcellular markers in NIH-3T3 fibroblasts ( $n \geq 4)$.

GalNAc addition are present and functional in both cell types. In addition, we tested the presence of the $\mathrm{O}$-glycan $\mathrm{T}$ antigen on the enzyme QSOX1, whose level we showed previously to be affected by the MFSD1 homolog of the fly (8). Secreted QSOX1-StrepTagII from MC-38 WT, MFSD1 ${ }^{-1-}$, and Cosmc $^{-/-}$cells (which lack the functional $\mathrm{T}$-synthase required for the generation of $\mathrm{T}$ antigen) was treated by sialidase to remove the terminal sialic acid, which allowed the detection of the $\mathrm{T}$ antigen by a specific antibody. While Cosmc ${ }^{-l-}$ cells did not have any $\mathrm{T}$ antigen, the levels of $\mathrm{T}$ antigen were indistinguishable between WT and MFSD1 ${ }^{-/-}$cells (Supplementary Figure 3B). In addition, the enzymatic activity of QSOX1-StrepTagII purified from MC-38 WT and MFSD1 ${ }^{-/-}$cells was indistinguishable (Supplementary Figure 3C). By liquid chromatography, we tested for differences in the N-glycan pool and found essentially identical retention profiles of $\mathrm{N}$-glycans isolated from WT and $\mathrm{MFSD1}^{-/-}$cells (Supplementary Figure 3D). As an example, the N-glycosylation of the heavily $\mathrm{N}$-glycosylated protein LAMP1 was not altered in $\mathrm{MFSD}^{-/-}$ compared with WT cells (Supplementary Figure 3E). We tested lectin binding to the cell surface of MC-38 WT and MFSD1 $1^{-/-}$ cells and could detect sialic acid (LPA), GlcNAc (WGA), and Gal (PNA) sugar-containing glycans on the cell surface, with the same abundance in both MC-38 genotypes (Supplementary Figures 3F, G). From these experiments, we conclude that most likely neither O- nor N-glycosylation is directly affected by MFSD1 in tumor cells.

\section{MFSD1 Has Minor Effects on Lysosomal Function}

We continued with a basic characterization of the endolysosomal system in MC-38 WT and $\mathrm{MFSD}^{-/-}$cells stained by LysoTracker. The size of the lysosomes in $\mathrm{MFSD}^{-/-}$was reduced by $9 \%$, while the activity of cathepsin $\mathrm{B}$, a protease used to measure lysosomal functionality, was increased by $26 \%$, compared with WT lysosomes (Supplementary Figure $\mathbf{3 H}$ ). The total number of lysosomes per cell and the $\mathrm{pH}$ in the endolysosomal system were not affected by the lack of MFSD1 (Supplementary Figure 3H).

\section{MFSD1 Affects $\beta 1$ Integrin and Adhesion Dynamics of Tumor Cells}

In cell culture, we observed faster detachment of MC-38 MFSD ${ }^{\mathrm{kd}}$ and $\mathrm{MFSD}^{-1-}$ compared with WT MC-38 cells (Supplementary Figures 3I, J) indicating weaker adhesion to the cell culture plates. We also observed faster spreading of $\mathrm{MFSD}^{-/-}$cells on uncoated and fibronectin-coated plates over time when compared with WT MC-38 cells (Figures 3A, B and Supplementary Figure 3K), suggesting that MFSD1 ${ }^{-/-}$cells have a faster turnover of binding sites, a condition which has previously been shown to promote metastasis (30). Therefore, we analyzed focal adhesions in MC-38 WT and $\mathrm{MFSD}^{-1-}$ cells by immunofluorescent staining of paxillin. Both paxillin fluorescent intensity (FI) and the average size of paxillin-stained focal adhesions were reduced in MFSD1 $1^{-/-}$ 
A
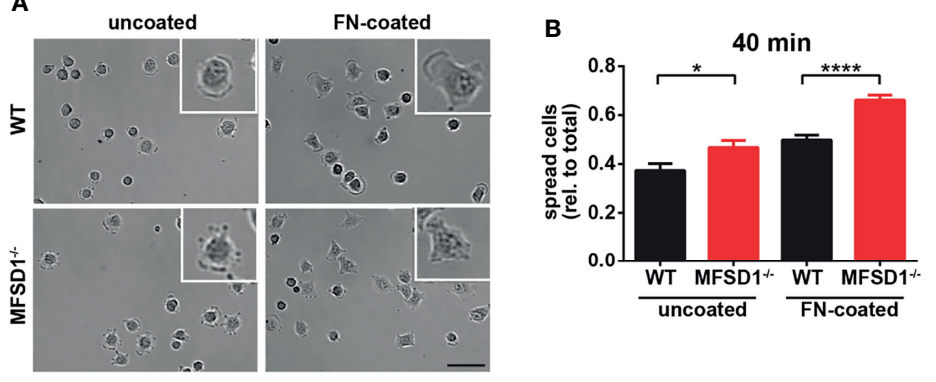

C

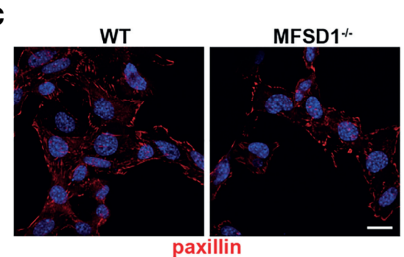

D
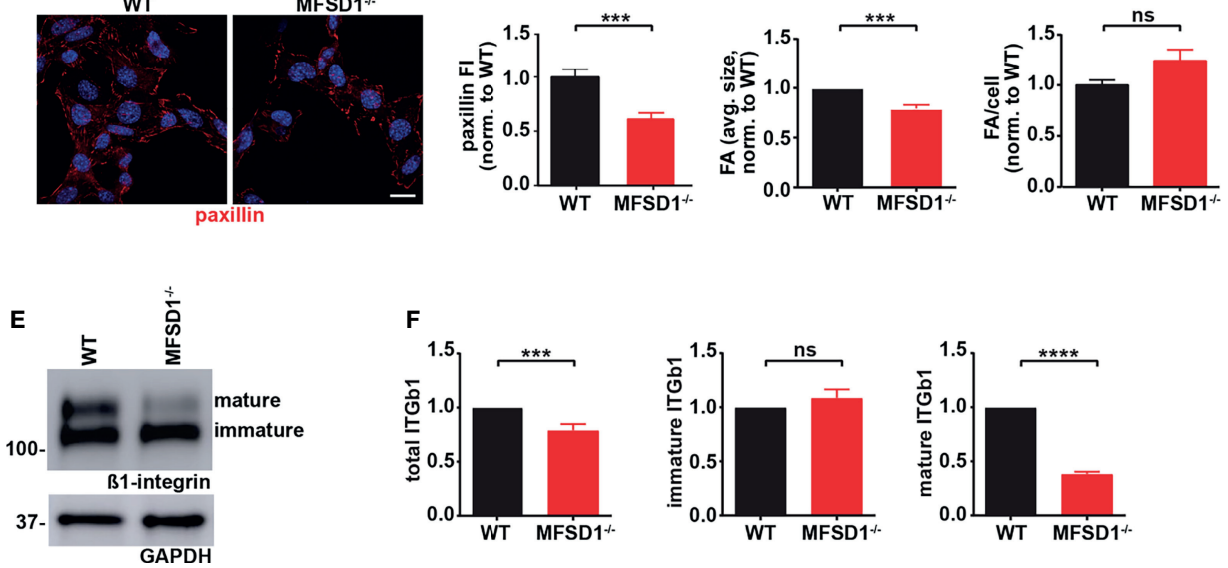

F
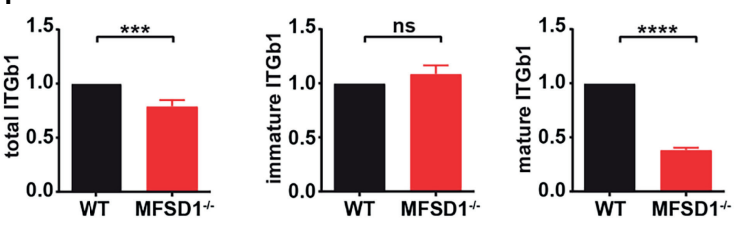

FIGURE 3 | MFSD1 controls cell adhesion dynamics. (A) Spreading assay of MC-38 WT and MFSD1 ${ }^{-1}$ on uncoated and FN-coated plates. Representative images after $40 \mathrm{~min}$ of spreading are shown. Magnified spread cell in the top right corner of each view field is shown. Bar $=50 \mu \mathrm{m}$. (B) Quantification of spreading assay at 40 min time point. Experiment was performed three times in duplicate or triplicate and three view fields were analyzed per condition ( $n \geq 21$ view fields). (C) Immunofluorescence of focal adhesions with paxillin staining in MC-38 WT and MFSD1 ${ }^{-/-}$cells. Bar $=10 \mu \mathrm{m}$. (D) Analysis of paxillin immunofluorescence staining. (E) Western blot of MC-38 WT and MFSD $1^{-/}$cells for $\beta 1$ integrin. GAPDH serves as a loading control. (F) Densitometric analysis of $\beta 1$ integrin detected by Western blots $(n=10)$. ${ }^{\star} p<0.05$; ${ }^{\star \star \star} p<0.001$; ${ }^{\star \star \star \star} p<0.0001 ;$ ns, not significant.

compared with WT cells, while the total number of focal adhesions per cell remained the same (Figures 3C, D). Focal adhesions link the actin cytoskeleton to the extracellular matrix via integrins. When we performed a Western blot of MC-38 WT and MFSD1 ${ }^{-1-}$ cells, we observed a double band of $\beta 1$ integrin, which changed in its relative intensity (Figure $\mathbf{3 E}$ ). When we quantified the $\beta 1$ integrin levels by densitometry, we detected that the overall amount of $\beta 1$ integrin was decreased in $\mathrm{MFSD}^{-/-}$when compared with WT cells (Figure 3F), while its mRNA levels were not affected (Supplementary Figure 3L). The level of the immature N-glycosylated lower $\beta 1$ integrin band was unaffected, but the level of the mature $\mathrm{N}$-glycosylated upper $\beta 1$ integrin band was decreased in MFSD $1^{-1-}$ when compared with WT MC-38 cells (Figure 3F). Thus, we observed that MFSD1 stabilizes focal adhesions and the maturely $\mathrm{N}$-glycosylated $\beta 1$ integrin protein in MC-38 tumor cells.

\section{MFSD1 Enhances the Stability of Maturely $\mathrm{N}$-glycosylated, Inactive $\beta 1$ Integrin}

We wished to further characterize the activation state of the different $\beta 1$ integrin forms we had observed in Western blots.
We, therefore, performed immunoprecipitation experiments on lysates from MC-38 WT and MFSD ${ }^{-1-}$ cells prepared from total cells or just the cell surface. While the conformation-insensitive $\beta 1$ integrin antibody clone HMb1-1 detected both forms of $\beta 1$ integrin, the active conformation-specific $\beta 1$ integrin antibody clone 9EG7 specifically immunoprecipitated only the lower $\beta 1$ integrin band from both samples (Figure 4A). We sought to test if the different sizes of the $\beta 1$ integrin bands are due to differential $\mathrm{N}$-glycan modification. Therefore, we treated lysates from MC-38 WT and MFSD1 ${ }^{-/-}$cells from the total cell and the intact cell surface with PNGaseF to remove all N-glycans. Immunoprecipitation with an antibody that recognizes all forms of $\beta 1$ integrin shows that PNGaseF treatment deglycosylated both bands and yields a single band of nonglycosylated $\beta 1$ integrin at $88 \mathrm{kDa}$ in all samples (Supplementary Figure 4A). Furthermore, the lower $\beta 1$ integrin band was indeed sensitive to EndoH treatment, being reduced to the size of the form lacking all glycosylation, indicating that the lower $\beta 1$ integrin band corresponds to an immaturely $\mathrm{N}$-glycosylated form. This result highlights that immaturely glycosylated $\beta 1$ integrin makes it to the cell surface and is predominantly in its active conformation. Summarizing, 


\section{A}
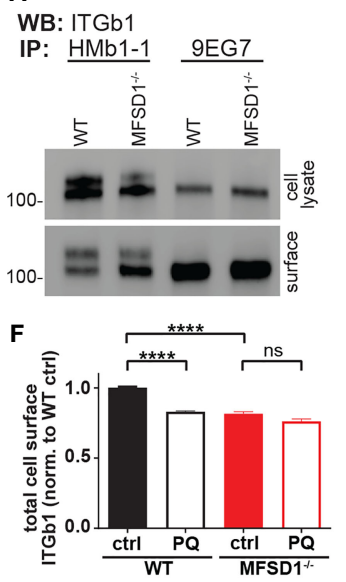

IP: ITGb1

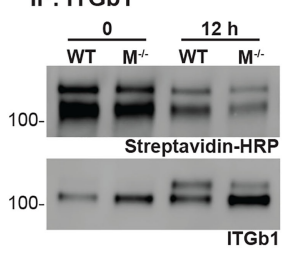

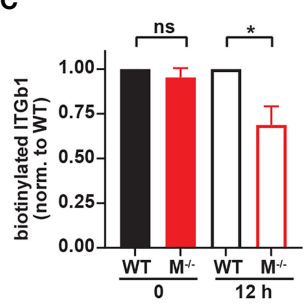

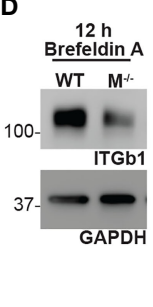

E

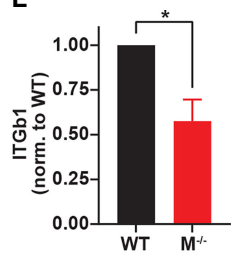

G

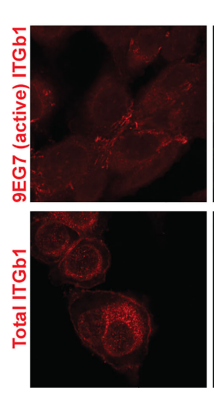

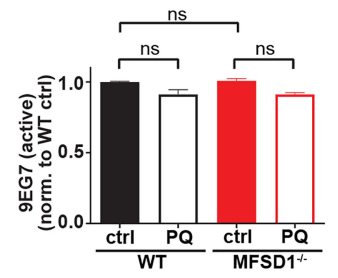

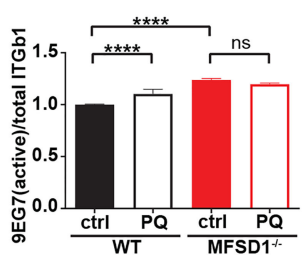

MFSD1eGFP

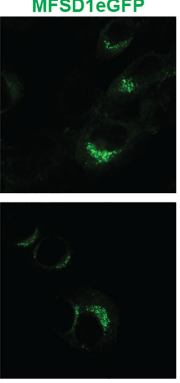

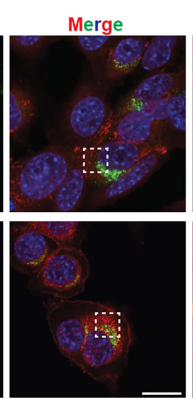

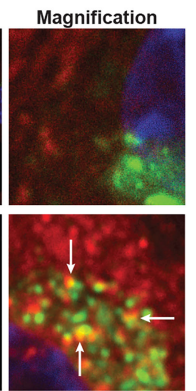

H

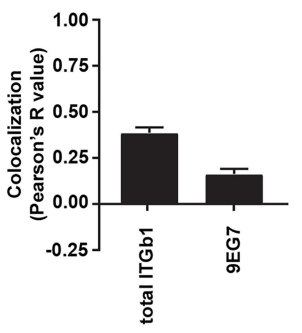

FIGURE 4 | MFSD1 promotes recycling and stabilization of inactive $\beta 1$ integrin. (A) Western blot of $\beta 1$ integrin immunoprecipitated by HMb1-1 or 9EG7 antibodies from total cell lysates or intact cell surface $(n=2)$. (B) Western blot of cell-surface biotinylated and immunoprecipitated $\beta 1$ integrin for biotinylation (streptavidin-HRP) at 0 and $12 \mathrm{~h}$ time point post-treatment (biotinylation). ITGb1 blot displays the input of $\beta 1$ integrin $(n=4)$. (C) Densitometric quantification of biotinylated $\beta 1$ integrin $(n=4)$. (D) Western blot of $\beta 1$ integrin upon brefeldin A treatment for $12 \mathrm{~h}$ (rate of $\beta 1$ integrin degradation experiment). GAPDH serves as a loading control. A representative experiment is shown. (E) Densitometric quantification of ITGb1 from brefeldin A-treated cells for $12 \mathrm{~h}(n=4)$. (F) Flow cytometric analysis of MC-38 WT and MFSD1 ${ }^{-1-}$ cells treated with recycling inhibitor primaquine $(\mathrm{PQ})$ or control $(n=7)$. (G) Co-immunofluorescence of MC-38 MFSD1-eGFP cells with an antibody detecting either the total (Itgb1) $(n=14)$ or the active conformation (9EG7) $(n=6)$ of $\beta 1$ integrin, respectively. The area indicated by a dashed square is shown magnified to the right. Arrows indicate co-localization. Bar $=10 \mu \mathrm{m}$. $\mathbf{( H )}$ Co-localization analysis of MFSD1-eGFP with the indicated $\beta 1$ integrin antibodies $(n \geq$ 10). ${ }^{*} p<0.05 ;{ }^{* \star \star *} p<0.0001$; ns, not significant.

our data show that MFSD1 stabilizes maturely N-glycosylated inactive $\beta 1$ integrin.

\section{MFSD1 Promotes Recycling and Thus Stabilization of Inactive $\beta 1$ Integrin}

We tested for an effect of MFSD1 on the degradation of $\beta 1$ integrin in MC-38 cells. We conducted surface biotinylation and, $12 \mathrm{~h}$ later, immunoprecipitated $\beta 1$ integrin and analyzed the level of biotinylated $\beta 1$ integrin that remained via streptavidin-HRP. While the input (time point $0 \mathrm{~h}$ ) of biotinylated proteins was roughly the same, $12 \mathrm{~h}$ later, $\mathrm{MFSD}^{-/-}$cells had significantly less biotinylated $\beta 1$ integrin left when compared with MC-38 WT control cells (Figures 4B, C). In addition, we blocked the de-novo feeding of proteins into the secretory pathway by treatment with brefeldin A. Twelve hours after treatment, the level of $\beta 1$ integrin, which at that time was purely in the mature $\mathrm{N}$ glycosylated form (Supplementary Figure 4B), was reduced to half in MC-38 MFSD1 ${ }^{-/-}$compared with WT cells (Figures 4D, E). Thus, MFSD1 stabilizes mature $\beta 1$ integrin.

To test if the recycling pathway is involved in $\beta 1$ integrin stabilization, we treated MC-38 WT and $\mathrm{MFSD}^{-1-}$ cells with primaquine, an established recycling inhibitor, and analyzed cellsurface $\beta 1$ integrin levels by flow cytometry. Primaquine treatment reduced the cell-surface levels of $\beta 1$ integrin in $\mathrm{MC}$ 38 WT cells to the levels seen in MFSD $1^{-1-}$ and increased the $\beta 1$ integrin activation index (ratio of active/total $\beta 1$ integrin). Strikingly, in $\mathrm{MFSD}^{-/-}$cells themselves, primaquine treatment did not further reduce the cell-surface levels of $\beta 1$ integrin or affect the activation index (Figure 4F). Consistent with this finding, we observed co-localization of total but not active $\beta 1$ integrin with MFSD1 (Figures 4G, H), arguing that MFSD1 primarily localizes with the inactive form. These data support the conclusion that MFSD1 enhances the recycling of $\beta 1$ integrin to the cell surface, particularly the mature $\mathrm{N}$-glycosylated inactive form, and protects it from lysosomal degradation. 


\section{MFSD1 Decreases the $\beta 1$ Integrin Activation Index, Suppressing Tumor Cell Migration}

We wished to assess integrin activity at the cell membrane to try to connect the capacity of MFSD1 to increase integrin maturation and focal adhesion size to its role in suppressing cell migration. To specifically analyze the cell-surface fraction of $\beta 1$ integrin, we conducted flow cytometry. We stained MC-38 cells with two antibodies detecting either total $\beta 1$ integrin (clone HMb1-1) or $\beta 1$ integrin in its active conformation (clone 9EG7). We observed a reduced amount of total $\beta 1$ integrin on the cell surface of MC-38 $\mathrm{MFSD}^{-/-}$cells when compared with WT cells, while the amount of active $\beta 1$ integrin remained the same (Figures 5A, B). This relative change leads to an increased $\beta 1$ integrin activation index in MFSD $1^{-1-}$ tumor cells, a state which has been associated with prometastatic features of tumor cells
A

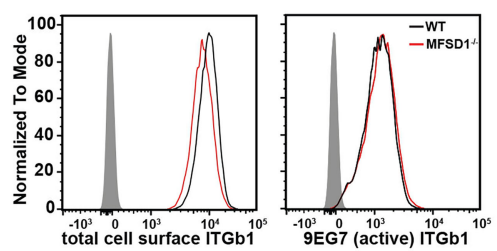

B

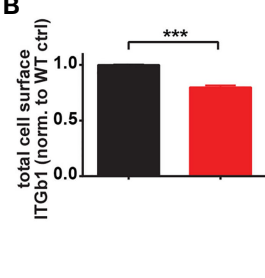

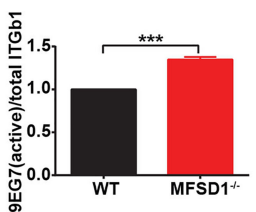

$\mathbf{F}$

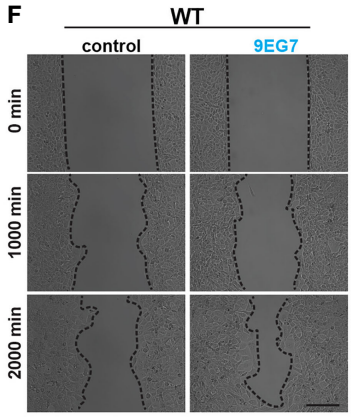

E

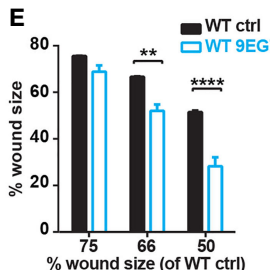

H

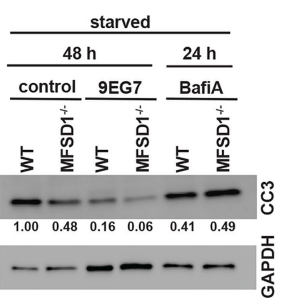

D
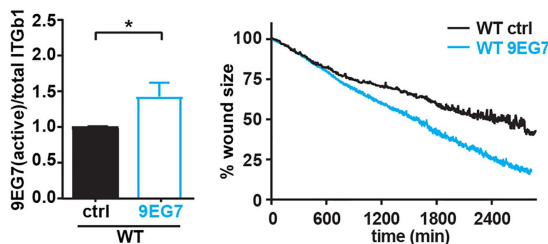

H
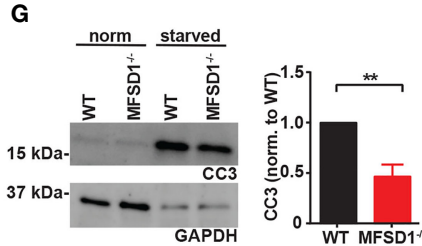

$\mathbf{J}$
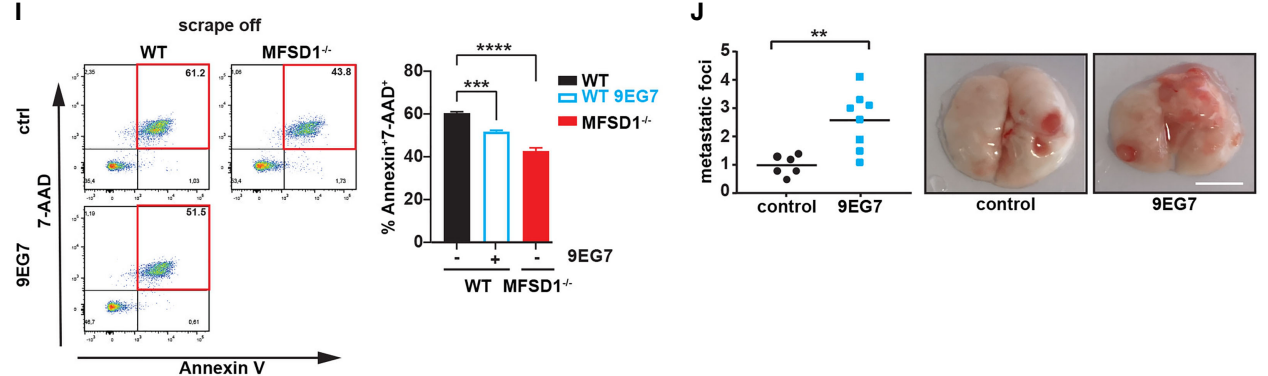

FIGURE 5 | MFSD1 decreases the $\beta 1$ integrin activation index, thereby suppressing tumor cell migration. (A) Representative flow cytometry analysis of MC-38 WT (black) and $\mathrm{MFSD}^{-1-}$ (red) cells stained with indicated antibodies. The gray-filled curve represents the isotype control staining. (B) Analysis of flow cytometry staining $(n=7)$. (C) $\beta 1$ Integrin activation index of cells treated with active conformation-specific $\beta 1$ integrin antibody clone 9EG7 $(n=4)$. (D) Representative graph of a wound closing assay with MC-38 WT cells treated with 9EG7 antibody (dotted lines) or control (solid lines). (E) Analysis of wound closing assay of MC-38 WT cells treated with 9EG7 antibody (empty bars) or control (filled bars) ( $n=3$ ). The \% wound size left of WT 9EG7 when WT cells have moved to shrink the wound to either $75 \%, 66 \%$, or $50 \%$ of the original size is depicted. (F) Representative images at indicated time points of one wound closing assay experiment. Bar $=200 \mu \mathrm{m}$. (G) Western blot of cells in normal cell culture medium and in the starvation medium for cleaved caspase 3 (CC3). GAPDH serves as a loading control $(n=6)$. (H) Western blot of cells previously starved from nutrients for $48 \mathrm{~h}$, control or treated with 9EG7 antibody, or $24 \mathrm{~h}$, control or treated with bafilomycin A $(n=2)$. The numbers at the bottom of the blot represent the densitometric analysis of the cleaved caspase 3 band. (I) Flow cytometric analysis of dead cells (AnnexinV+7-AAD+) upon scraping (= mechanical stress) from cell culture plates. Cells have been treated with 9EG7 antibody or left untreated (control) $(n \geq 4)$. (J) Experimental metastasis of MC-38 WT cells pretreated with the $\beta 1$ integrin activating antibody $9 \mathrm{EG7}$ and the control, respectively. The relative number (normalized to the mean seen in the control) of macroscopic metastatic foci per lung is shown (control, $n=6 ; 9 \mathrm{EG} 7$ treated, $n=8$ ). Representative images of the lungs are shown on the right. Scale bar $=0.5 \mathrm{~cm} .{ }^{\star} p<0.05 ;{ }^{\star \star} p<0.01 ;{ }^{* \star \star} p<0.001 ;{ }^{* \star \star \star} p<0.0001$. 
(14). Thus, these data support the conclusion that MFSD1 normally reduces the $\beta 1$ integrin activation index at the cell surface. Furthermore, in combination with the data from Figure 4, our data support the conclusion that the stabilization of inactive maturely $\mathrm{N}$-glycosylated $\beta 1$ integrin by MFSD1 contributes to the decrease in the activation index of $\beta 1$ integrin, suppressing the migration of wild-type tumor cells.

We wished to directly test the connection between $\beta 1$ integrin activity and migration. We therefore incubated WT cells with the active conformation-specific $\beta 1$ integrin antibody clone 9EG7. Upon 9EG7 treatment, we observed an increased $\beta 1$ integrin activation index as measured by flow cytometry (Figure 5C), without affecting the total amount of cell-surface $\beta 1$ integrin (Supplementary Figure 5A). Consistent with what we observed for $\mathrm{MFSD}^{-1-}$ cells, these WT 9EG7-treated cells displayed faster migration in the wound closing assay (Figures 5D-F). These data argue that suppression by MFSD1 of the relative amount of active $\beta 1$ integrin at the cell surface aids in repressing faster migration of tumor cells.

\section{Suppression by MFSD1 of the $\beta 1$ Integrin Activation Index Increases Tumor Cell Sensitivity to Nutrient Starvation and Mechanical Stress}

$\beta 1$ Integrin signaling positively regulates among other biological pathways the survival of tumor cells under stressed conditions, including shear stress in vascular circulation and the adaptation to changing metabolic demands $(13,14,31,32)$. To test if the increase in the $\beta 1$ integrin activation index observed in MFSD $^{-1-}$ cells affects their survival, we starved cells of nutrients for 2 days and we assessed apoptotic induction by detecting cleaved caspase 3 (CC3) via Western blotting. As expected, $\mathrm{MFSD}^{-/-}$cells displayed less apoptotic induction compared with WT cells (Figure 5G). Interestingly, blocking lysosomal function by incubating cells with bafilomycin A diminished the protective effect provided to the cells by the loss of MFSD1 ${ }^{-1-}$ (Figure 5H). The starvation-induced apoptosis of WT cells was rescued by incubating cells with the 9EG7 antibody to increase the $\beta 1$ integrin activation index, supporting the conclusion that the effect observed in MFSD1 is due to an effect on $\beta 1$ integrin. Tumor cells are exposed to shear stress in the vasculature during metastatic spread. To mimic mechanical stress, we scraped off MC-38 WT and $\mathrm{MFSD}^{-/-}$cells with a rubber cell scraper from cell culture plates and analyzed cells with apoptosis markers via flow cytometry. We observed that WT cells are more sensitive to mechanical stress-induced cell death (7-AAD ${ }^{+}$Annexin $V^{+}$cells) than $\mathrm{MFSD}^{-/-}$cells (Figure 5I). WT cells increased their resistance to mechanical stress upon treatment with the 9EG7 antibody to increase their $\beta 1$ integrin activation (Figure 5I). These results strongly suggest that the capacity of MFSD1 to decrease the $\beta 1$ integrin activation index in MC-38 cells is a contributing factor to its ability to suppress metastasis, by depressing tumor cell migration and increasing the propensity of tumor cells to die upon starvation or mechanical stress. To address this hypothesis in an in vivo experiment, we analyzed the pulmonary metastatic burden of mice injected with 9EG7-pretreated MC-38 WT cells. Indeed, 9EG7-pretreated MC-38WT cells were more potent in generating pulmonary metastases than control untreated cells (Figure 5J). This result confirms that the features supported by an increased activation index of $\beta 1$ integrin described by the aforementioned experiments, namely, increased migration, mechanical stress, and starvation resistance, directly lead to an increased metastatic burden.

\section{Reduced MFSD1 Expression Happens Early During Tumorigenesis}

Since we observed that MFSD1 suppresses colon cancer cell migration, we first searched for a linkage of MFSD1 expression levels and the prognosis of colon adenocarcinoma patients, but found no correlation (data not shown). Therefore, we analyzed the expression levels of MFSD1 during tumor formation. We compared publicly available gene expression data from publications comparing gene expression in healthy normal mucosa and colorectal adenoma tissue, or primary colorectal tumor tissue, and found that in each of the four GEO datasets examined (33-36), the expression levels of MFSD1 were reduced in tumor tissue when compared with healthy mucosa (Figure 6A). Thus, early reduction in MFSD1 expression might be beneficial for tumor cells to acquire hallmarks of cancer.

\section{Reduced MFSD1 Expression Is Associated With Poor Prognosis of Selected Tumor Patients}

We also screened data available on the Kaplan-Meier plotter page for the association of MFSD1 expression (mRNA gene chip) and the prognosis of lung, breast, and gastric tumor patients (37). Lung adenocarcinoma patients with high MFSD1 expression had a median overall survival of 150 months, compared with 72.3 months in the low expression cohort (the patient group was split at the median) (Figure 6B), while the prognoses of lung squamous cell carcinoma patients were unaffected by MFSD1 expression (data not shown). The same was true for gastric cancer patients, where the median survival in the high MFDS1 expression cohort and in the low expression cohort was 70.2 and 22.5 months, respectively (Figure 6C). Refractory free survival of triple-negative breast cancer patients was significantly reduced in patients with low MFSD1 expression (Figure 6D) with a survival of the low expression cohort of 19.81 months compared with 55.2 months in the high expression cohort. These data clearly establish that MFSD1 expression correlates with patient outcome for certain tumor types.

In addition, we checked for an association of GLMP or $\beta 1$ integrin expression (mRNA gene chip) and the prognosis of the aforementioned tumor patients. We found no association for GLMP (data not shown), potentially indicating that changes in GLMP mRNA levels do not translate directly into changed protein levels. 


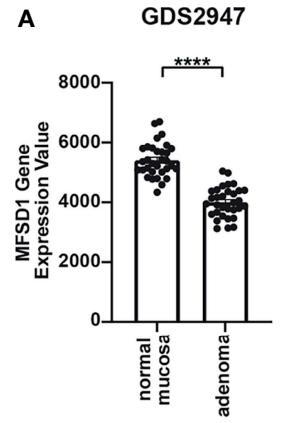

B

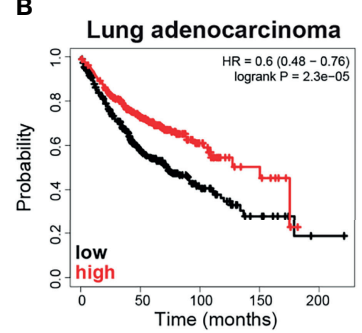

GDS2609

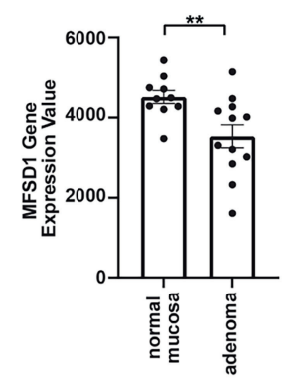

C

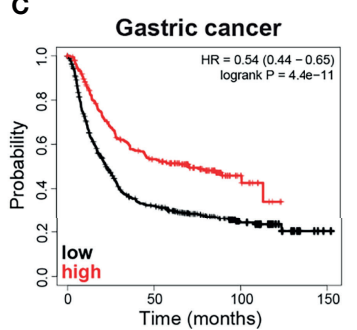

GDS5232
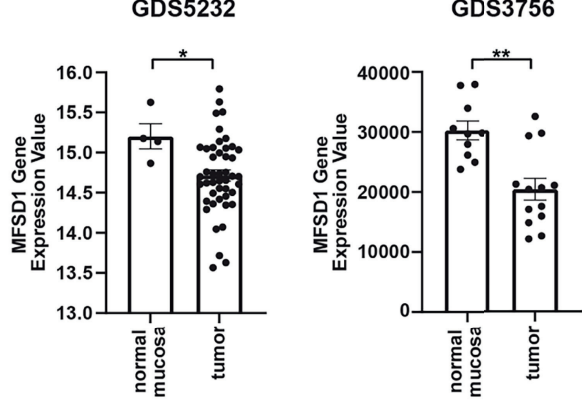

D

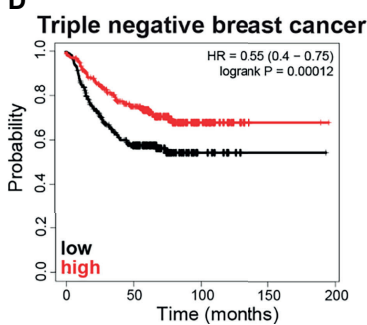

FIGURE 6 | MFSD1 expression levels are reduced in colorectal adenomas and inversely correlate with patient survival in lung, gastric, and triple-negative breast cancer. (A) MFSD1 gene expression values were obtained from the indicated GEO datasets. (B-D) KM plotter graph of the respective patient prognosis. Low or high expression levels of MFSD1 are indicated by a black or red line, respectively. ${ }^{*} p<0.05 ;{ }^{* \star} p<0.01 ;{ }^{\star \star \star \star} p<0.0001$.

However, we did find an association of the $\beta 1$ integrin expression level (mRNA gene chip) with the prognosis of lung, breast, and gastric tumor patients (37). Specifically, when we analyzed the patient prognosis for the highest $(\mathrm{Q} 1)$ and lowest (Q4) expressing quartile of $\beta 1$ integrin (Supplementary Figure 6), we found that lung adenocarcinoma patients represented in Q4 had a mean overall survival of 76 months compared with 107 months for patients in Q1, and $\beta 1$ integrin expression levels significantly correlated with overall survival. For gastric cancer Q4 patients, the mean overall survival was 24.8 months compared with 30.4 months for patients in Q1 (statistically not significant). In addition, in triple-negative breast cancer patients, Q4 patients had a mean refractory free survival of 21.9 months compared with 33.6 months for patients in Q1 (statistically not significant). For the three cancer types studied, this supports the conclusion that reduced levels of $\beta 1$ integrin support a faster progress of the disease.

\section{DISCUSSION}

Despite their crucial role in regulating the distribution of small molecules across membranes, the function of about one-third of SLCs remains unknown (1), including MFSD1. Here, we identify a cell biological function regulated by MFSD1, namely, the recycling of $\beta 1$ integrin from the endolysosomal system, utilizing a murine colon carcinoma cell line. We show that this capacity underlies the regulation by MFSD1 of migration.

MFSD1 restrained migration in the three tumor cell lines we tested. $\mathrm{MFSD1}^{-1-}$ colon carcinoma cells displayed smaller individual focal adhesions and increased spreading when plated on control and FN-precoated cell culture plates, as compared with WT cells. Smaller focal adhesions support faster migration (38) with a biphasic dependence of cell migration on focal adhesion size (39). We also observed that $\mathrm{MFSD}^{-/-}$colon carcinoma cells detached faster from cell culture plates than WT cells, consistent with the higher turnover of focal adhesions. Increased focal adhesion turnover and focal adhesion disassembly can lead to faster in vitro 2D migration $(40,41)$ and increased incidence of in vivo metastasis $(30,42)$. Furthermore, focal adhesion disassembly was shown to be increased in invasive versus non-invasive breast cancer cells (30). Our findings support the conclusion that MFSD1 decreases tumor migratory speed by increasing focal adhesion size and stability.

Integrin is a key component of focal adhesions. The measure of the amount of active $\beta 1$ integrin in comparison to the total $\beta 1$ integrin is deemed the integrin activation index. The link between a higher integrin activity index and tumor progression or cell migration is well established (13, 14, 43-48). For example, metastatic breast cancer and melanoma have increased activated $\beta 1$ integrin compared with the respective primary tumor (44). Furthermore, constitutively active $\beta 1$ integrin L358A has an increased activation index when compared with WT $\beta 1$ integrin expression and leads to increased liver metastasis of B16F10 melanoma (44). Thus, we hypothesize that MFSD1 serves as a suppressor of metastasis through its restraint of integrin activity. As we observed for $\mathrm{MFSD1}^{-/-}$colon carcinoma cells, in HEK293 or MDA-MB-231 cells mutated for Shank 1 or 3 , a higher $\beta 1$ integrin activation index was 
associated with reduced adhesion area, increased cell spreading, and faster migration (49). Thus, we hypothesize that MFSD1 increases focal adhesion size and stability and reduces migration speed by limiting the integrin activation index.

Cell-surface integrins have a half-life of 12-24 $\mathrm{h}$ and the majority of endocytosed integrin is recycled back to the cell surface (15), with active and inactive integrins using different routes and kinetics (50). Recycling via SNX17 has been shown to be crucial for the protection of $\beta 1$ integrin from lysosomal degradation $(51,52)$. Differential recycling kinetics and thus protection from lysosomal degradation of the inactive or active form could lead to changes in the activation index of integrin. Our data are consistent with the stabilization by MFSD1 of the inactive form of $\beta 1$ integrin through stimulation of its recycling back to the cell surface, lowering the activation index. The converse action, recycling and stabilization of active $\beta 1$ integrin, can be enhanced by CLIC3 or GGA2; fittingly, both of these proteins stimulate the opposite phenotype for migration, namely, efficient cell migration $(53,54)$. We find MFSD1 localized to the endolysosomal system in colon carcinoma cells and fibroblasts, just as we have observed previously for its fly ortholog, Mrva, in macrophages (8). However, MFSD1 had a different effect on cell migration in the fly and the mammalian tumor cell system. This could be due to different effects of changes in the integrin activation on the two cell types (55, 56). We hypothesize that MFSD1 enhances the recycling of $\beta 1$ integrin and that a loss of MFSD1 leads to a changed metabolite milieu in the endolysosomal system affecting the proper function of proteins involved in the recycling of $\beta 1$ integrin. Enhanced recycling of inactive $\beta 1$ integrin, stimulated by MFSD1, would save $\beta 1$ integrin from degradation, resulting in a reduced integrin activation index. Supporting this hypothesis is also the fact that MFSD1 co-localizes partially with recycling Rab $11^{+}$endosomes and total $\beta 1$ integrin and fails to co-localize with active $\beta 1$ integrin.

Integrin activity is normally controlled by $\mathrm{N}$-glycosylation. Removing the N-glycan site at N343 of $\beta 1$ integrin greatly enhanced the fibronectin binding of the mutant $\alpha 5 \beta 1$ integrin compared with the control, indicating that this N-glycan site sterically impairs the active conformation or hinders ligand binding (57). Mature glycosylated $\beta 1$ integrin could be induced to have an active conformation in the presence of activating fibronectin ligand (58), indicating that $\mathrm{N}$-glycosylation represses intrinsic $\beta 1$ integrin activation, but allows outside-in activation. We and others have identified that immaturely $\mathrm{N}$-glycosylated $\beta 1$ integrin is constitutively in its active conformation (58). We report here the presence of this form of $\beta 1$ integrin on the cell surface of the murine colon carcinoma cell line MC-38 through the use of the active conformation-specific 9EG7 integrin antibody (59). The same antibody was used to detect this immaturely glycosylated $\beta 1$ integrin on the cell surface of the astrocytoma cell line A172, functionally bound to fibronectin (60). This suggests that certain tumor cells manage to circumvent glycosylation control on $\beta 1$ integrin by transporting the immaturely glycosylated form to the cell surface. Our work argues that one of the ways in which the cell suppresses tumor formation enhanced by this routing of immaturely glycosylated integrin to the cell surface is by employing MFSD1 to enhance the recycling of maturely glycosylated $\beta 1$ integrin back to the cell surface to dilute out the activated forms.

MFSD1 expression levels correlate with the survival of patients with lung, breast, and gastric tumors, and downregulation of MFSD1 expression happens during early events of colon tumorigenesis. By employing two different tumor cell lines in an experimental metastasis, as well as a third in an orthotopic spontaneous metastasis setting, we observed that MFSD1 restrains metastatic spread. Drugs capable of enhancing MFSD1 activity or its expression could thus potentially aid in inhibiting the progression of certain tumors. However, to substantiate the role of MFSD1 during tumorigenesis and metastatic spread, further experiments with genetic tumor mouse models displaying metastatic disease are required. In addition, given the published effects of MFSD1 involving endothelial cells (10), it will be of high interest to also investigate the contribution of stromal cell MFSD1 during tumor disease progression. In future studies, we also aim to unravel the molecular function of MFSD1, aiding the development of drugs potentially useful for therapeutic intervention.

\section{DATA AVAILABILITY STATEMENT}

The raw data supporting the conclusions of this article will be made available by the authors, without undue reservation.

\section{ETHICS STATEMENT}

The animal study was reviewed and approved by the Veterinary Office of the Kanton Zürich, Switzerland.

\section{AUTHOR CONTRIBUTIONS}

MR and DS contributed to the conception and design of the study, analyzed and interpreted the data, and wrote the manuscript. MR and JB performed all but the specifically mentioned experiments. RS analyzed the patient data. BS and $\mathrm{MO}$ performed the CORA analysis and the N-glycan profiling. $\mathrm{MG}$ and LB performed the in vivo metastasis experiments. MD contributed essential material. AG cloned the recombinant expression constructs. All authors contributed to the article and approved the submitted version.

\section{FUNDING}

MR and DS were funded by the NO Forschungs- und Bildungsges.m.b.H. (LS16-021) and IST core funding. MD was funded by Deutsche Forschungsgemeinschaft (DA 1785-1). 


\section{ACKNOWLEDGMENTS}

We thank M. Sixt, A. Leithner, and J. Alanko for helpful advice and the BioImaging Facility at IST Austria for technical support and assistance. We thank the Siekhaus Lab for the careful review of the manuscript and their input.

\section{REFERENCES}

1. Cesar-Razquin A, Snijder B, Frappier-Brinton T, Isserlin R, Gyimesi G, Bai X, et al. A Call for Systematic Research on Solute Carriers. Cell (2015) 162:47887. doi: 10.1016/j.cell.2015.07.022

2. Lin L, Yee SW, Kim RB, Giacomini KM. SLC Transporters as Therapeutic Targets: Emerging Opportunities. Nat Rev Drug Discov (2015) 14:543-60. doi: $10.1038 / \mathrm{nrd} 4626$

3. Ayka A, Sehirli AO. The Role of the SLC Transporters Protein in the Neurodegenerative Disorders. Clin Psychopharmacol Neurosci (2020) 18:174-87. doi: 10.9758/cpn.2020.18.2.174

4. Rask-Andersen M, Masuram S, Fredriksson R, Schioth HB. Solute Carriers as Drug Targets: Current Use, Clinical Trials and Prospective. Mol Aspects Med (2013) 34:702-10. doi: 10.1016/j.mam.2012.07.015

5. Schumann T, Konig J, Henke C, Willmes DM, Bornstein SR, Jordan J, et al. Solute Carrier Transporters as Potential Targets for the Treatment of Metabolic Disease. Pharmacol Rev (2020) 72:343-79. doi: 10.1124/pr.118.015735

6. Wu Z, Xu J, Liang C, Meng Q, Hua J, Wang W, et al. Emerging Roles of the Solute Carrier Family in Pancreatic Cancer. Clin Transl Med (2021) 11:e356. doi: $10.1002 / \mathrm{ctm} 2.356$

7. Wang WW, Gallo L, Jadhav A, Hawkins R, Parker CG. The Druggability of Solute Carriers. J Med Chem (2020) 63:3834-67. doi: 10.1021/acs.jmedchem. 9 b01237

8. Valoskova K, Biebl J, Roblek M, Emtenani S, Gyoergy A, Misova M, et al. A Conserved Major Facilitator Superfamily Member Orchestrates a Subset of OGlycosylation to Aid Macrophage Tissue Invasion. Elife (2019) 8. doi: 10.7554/eLife.41801

9. Chapel A, Kieffer-Jaquinod S, Sagne C, Verdon Q, Ivaldi C, Mellal M, et al. An Extended Proteome Map of the Lysosomal Membrane Reveals Novel Potential Transporters. Mol Cell Proteomics (2013) 12:1572-88. doi: 10.1074/mcp.M112.021980

10. Massa Lopez D, Thelen M, Stahl F, Thiel C, Linhorst A, Sylvester M, et al. The Lysosomal Transporter MFSD1 Is Essential for Liver Homeostasis and Critically Depends on its Accessory Subunit GLMP. Elife (2019) 8. doi: 10.7554/eLife.50025

11. Lopez DM, Kahlau L, Jungnickel KEJ, Low C, Damme M. Characterization of the Complex of the Lysosomal Membrane Transporter MFSD1 and Its Accessory Subunit GLMP. FASEB J (2020) 34:14695-709. doi: 10.1096/ fj.202000912RR

12. Siekhaus D, Haesemeyer M, Moffitt O, Lehmann R. RhoL Controls Invasion and Rap1 Localization During Immune Cell Transmigration in Drosophila. Nat Cell Biol (2010) 12:605-10. doi: 10.1038/ncb2063

13. Cooper J, Giancotti FG. Integrin Signaling in Cancer: Mechanotransduction, Stemness, Epithelial Plasticity, and Therapeutic Resistance. Cancer Cell (2019) 35:347-67. doi: 10.1016/j.ccell.2019.01.007

14. Hamidi H, Ivaska J. Every Step of the Way: Integrins in Cancer Progression and Metastasis. Nat Rev Cancer (2018) 18:533-48. doi: 10.1038/s41568-0180038-z

15. Paul NR, Jacquemet G, Caswell PT. Endocytic Trafficking of Integrins in Cell Migration. Curr Biol (2015) 25:R1092-105. doi: 10.1016/j.cub.2015.09.049

16. Hou J, Yan D, Liu Y, Huang P, Cui H. The Roles of Integrin Alpha5betal in Human Cancer. Onco Targets Ther (2020) 13:13329-44. doi: 10.2147/ OTT.S273803

17. Marsico G, Russo L, Quondamatteo F, Pandit A. Glycosylation and Integrin Regulation in Cancer. Trends Cancer (2018) 4:537-52. doi: 10.1016/j.trecan. 2018.05.009

18. Corbett TH, Griswold DPJr., Roberts BJ, Peckham JC, Schabel FMJr. Tumor Induction Relationships in Development of Transplantable Cancers of the Colon in Mice for Chemotherapy Assays, With a Note on Carcinogen Structure. Cancer Res (1975) 35:2434-9.

\section{SUPPLEMENTARY MATERIAL}

The Supplementary Material for this article can be found online at: https://www.frontiersin.org/articles/10.3389/fonc.2022.777634/ full\#supplementary-material

19. Poste G, Doll J, Hart IR, Fidler IJ. In Vitro Selection of Murine B16 Melanoma Variants With Enhanced Tissue-Invasive Properties. Cancer Res (1980) 40:1636-44.

20. Meerbrey KL, Hu G, Kessler JD, Roarty K, Li MZ, Fang JE, et al. The pINDUCER Lentiviral Toolkit for Inducible RNA Interference In Vitro and In Vivo. Proc Natl Acad Sci USA (2011) 108:3665-70. doi: 10.1073/pnas.1019736108

21. Bohm CM, Mulder MC, Zennadi R, Notter M, Schmitt-Graff A, Finn OJ, et al. Carbohydrate Recognition on MUC1-Expressing Targets Enhances Cytotoxicity of a T Cell Subpopulation. Scand J Immunol (1997) 46:27-34. doi: 10.1046/j.1365-3083.1996.d01-91.x

22. Ilani T, Alon A, Grossman I, Horowitz B, Kartvelishvily E, Cohen SR, et al. A Secreted Disulfide Catalyst Controls Extracellular Matrix Composition and Function. Science (2013) 341:74-6. doi: 10.1126/science.1238279

23. Humphries MJ. Cell Adhesion Assays. Mol Biotechnol (2001) 18:57-61. doi: 10.1385/MB:18:1:57

24. Kudelka MR, Antonopoulos A, Wang Y, Duong DM, Song X, Seyfried NT, et al. Cellular O-Glycome Reporter/Amplification to Explore O-Glycans of Living Cells. Nat Methods (2016) 13:81-6. doi: 10.1038/nmeth.3675

25. Szulc B, Sosicka P, Maszczak-Seneczko D, Skurska E, Shauchuk A, Olczak T, et al. Biosynthesis of GlcNAc-Rich N- and O-Glycans in the Golgi Apparatus Does Not Require the Nucleotide Sugar Transporter SLC35A3. J Biol Chem (2020) 295:16445-63. doi: 10.1074/jbc.RA119.012362

26. Sosicka P, Bazan B, Maszczak-Seneczko D, Shauchuk Y, Olczak T, Olczak M. SLC35A5 Protein-A Golgi Complex Member With Putative Nucleotide Sugar Transport Activity. Int J Mol Sci (2019) 20(2):276. doi: 10.3390/ijms20020276

27. Bigge JC, Patel TP, Bruce JA, Goulding PN, Charles SM, Parekh RB. Nonselective and Efficient Fluorescent Labeling of Glycans Using 2-Amino Benzamide and Anthranilic Acid. Anal Biochem (1995) 230:229-38. doi 10.1006/abio.1995.1468

28. Hauselmann I, Borsig L. Altered Tumor-Cell Glycosylation Promotes Metastasis. Front Oncol (2014) 4:28. doi: 10.3389/fonc.2014.00028

29. Glavey SV, Huynh D, Reagan MR, Manier S, Moschetta M, Kawano Y, et al. The Cancer Glycome: Carbohydrates as Mediators of Metastasis. Blood Rev (2015) 29:269-79. doi: 10.1016/j.blre.2015.01.003

30. Bijian K, Lougheed C, Su J, Xu B, Yu H, Wu JH, et al. Targeting Focal Adhesion Turnover in Invasive Breast Cancer Cells by the Purine Derivative Reversine. Br J Cancer (2013) 109:2810-8. doi: 10.1038/bjc.2013.675

31. Strilic B, Offermanns S. Intravascular Survival and Extravasation of Tumor Cells. Cancer Cell (2017) 32:282-93. doi: 10.1016/j.ccell.2017.07.001

32. Ata R, Antonescu CN. Integrins and Cell Metabolism: An Intimate Relationship Impacting Cancer. Int J Mol Sci (2017) 18(1):189. doi: 10.3390/ijms18010189

33. Snipstad K, Fenton CG, Kjaeve J, Cui G, Anderssen E, Paulssen RH. New Specific Molecular Targets for Radio-Chemotherapy of Rectal Cancer. Mol Oncol (2010) 4:52-64. doi: 10.1016/j.molonc.2009.11.002

34. Agesen TH, Berg M, Clancy T, Thiis-Evensen E, Cekaite L, Lind GE, et al. CLC and IFNAR1 are Differentially Expressed and a Global Immunity Score Is Distinct Between Early- and Late-Onset Colorectal Cancer. Genes Immun (2011) 12:653-62. doi: 10.1038/gene.2011.43

35. Hong Y, Ho KS, Eu KW, Cheah PY. A Susceptibility Gene Set for Early Onset Colorectal Cancer That Integrates Diverse Signaling Pathways: Implication for Tumorigenesis. Clin Cancer Res (2007) 13:1107-14. doi: 10.1158/10780432.CCR-06-1633

36. Sabates-Bellver J, van der Flier LG, de Palo M, Cattaneo E, Maake C, Rehrauer $\mathrm{H}$, et al. Transcriptome Profile of Human Colorectal Adenomas. Mol Cancer Res (2007) 5:1263-75. doi: 10.1158/1541-7786.MCR-07-0267

37. Lanczky A, Gyorffy B. Web-Based Survival Analysis Tool Tailored for Medical Research (KMplot): Development and Implementation. J Med Internet Res (2021) 23:e27633. doi: 10.2196/27633

38. Kim DH, Wirtz D. Predicting How Cells Spread and Migrate: Focal Adhesion Size Does Matter. Cell Adh Migr (2013) 7:293-6. doi: 10.4161/cam.24804 
39. Kim DH, Wirtz D. Focal Adhesion Size Uniquely Predicts Cell Migration. FASEB J (2013) 27:1351-61. doi: 10.1096/fj.12-220160

40. Kenific CM, Stehbens SJ, Goldsmith J, Leidal AM, Faure N, Ye J, et al. NBR1 Enables Autophagy-Dependent Focal Adhesion Turnover. J Cell Biol (2016) 212:577-90. doi: 10.1083/jcb.201503075

41. Zhong J, Baquiran JB, Bonakdar N, Lees J, Ching YW, Pugacheva E, et al. NEDD9 Stabilizes Focal Adhesions, Increases Binding to the Extra-Cellular Matrix and Differentially Effects 2D Versus 3D Cell Migration. PloS One (2012) 7:e35058. doi: 10.1371/journal.pone.0035058

42. Chang CH, Bijian K, Qiu D, Su J, Saad A, Dahabieh MS, et al. Endosomal Sorting and C-Cbl Targeting of Paxillin to Autophagosomes Regulate CellMatrix Adhesion Turnover in Human Breast Cancer Cells. Oncotarget (2017) 8:31199-214. doi: 10.18632/oncotarget.16105

43. Felding-Habermann B, O'Toole TE, Smith JW, Fransvea E, Ruggeri ZM, Ginsberg MH, et al. Integrin Activation Controls Metastasis in Human Breast Cancer. Proc Natl Acad Sci USA (2001) 98:1853-8. doi: 10.1073/pnas.98.4.1853

44. Kato H, Liao Z, Mitsios JV, Wang HY, Deryugina EI, Varner JA, et al. The Primacy of Betal Integrin Activation in the Metastatic Cascade. PloS One (2012) 7:e46576. doi: 10.1371/journal.pone.0046576

45. Margadant C, Kreft M, Zambruno G, Sonnenberg A. Kindlin-1 Regulates Integrin Dynamics and Adhesion Turnover. PloS One (2013) 8:e65341. doi: 10.1371/journal.pone.0065341

46. Sokeland G, Schumacher U. The Functional Role of Integrins During Intraand Extravasation Within the Metastatic Cascade. Mol Cancer (2019) 18:12. doi: 10.1186/s12943-018-0937-3

47. Lee YC, Jin JK, Cheng CJ, Huang CF, Song JH, Huang M, et al. Targeting Constitutively Activated Beta1 Integrins Inhibits Prostate Cancer Metastasis. Mol Cancer Res (2013) 11:405-17. doi: 10.1158/1541-7786.MCR-12-0551

48. Pellinen T, Rantala JK, Arjonen A, Mpindi JP, Kallioniemi O, Ivaska J. A Functional Genetic Screen Reveals New Regulators of Betal-Integrin Activity. J Cell Sci (2012) 125:649-61. doi: 10.1242/jcs.090704

49. Lilja J, Zacharchenko T, Georgiadou M, Jacquemet G, De Franceschi N, Peuhu E, et al. SHANK Proteins Limit Integrin Activation by Directly Interacting With Rap1 and R-Ras. Nat Cell Biol (2017) 19:292-305. doi: 10.1038/ncb3487

50. Arjonen A, Alanko J, Veltel S, Ivaska J. Distinct Recycling of Active and Inactive Betal Integrins. Traffic (2012) 13:610-25. doi: 10.1111/j.16000854.2012.01327.x

51. Steinberg F, Heesom KJ, Bass MD, Cullen PJ. SNX17 Protects Integrins From Degradation by Sorting Between Lysosomal and Recycling Pathways. J Cell Biol (2012) 197:219-30. doi: 10.1083/jcb.201111121

52. Bottcher RT, Stremmel C, Meves A, Meyer H, Widmaier M, Tseng HY, et al. Sorting Nexin 17 Prevents Lysosomal Degradation of Betal Integrins by Binding to the Betal-Integrin Tail. Nat Cell Biol (2012) 14:584-92. doi: $10.1038 /$ ncb2501
53. Dozynkiewicz MA, Jamieson NB, Macpherson I, Grindlay J, van den Berghe PV, von Thun A, et al. Rab25 and CLIC3 Collaborate to Promote Integrin Recycling From Late Endosomes/Lysosomes and Drive Cancer Progression. Dev Cell (2012) 22:131-45. doi: 10.1016/j.devcel.2011.11.008

54. Sahgal P, Alanko J, Icha J, Paatero I, Hamidi H, Arjonen A, et al. GGA2 and RAB13 Promote Activity-Dependent Betal-Integrin Recycling. J Cell Sci (2019) 132. doi: $10.1242 /$ jcs. 233387

55. Friedl P, Brocker EB, Zanker KS. Integrins, Cell Matrix Interactions and Cell Migration Strategies: Fundamental Differences in Leukocytes and Tumor Cells. Cell Adhes Commun (1998) 6:225-36. doi: 10.3109/15419069809004478

56. Brakebusch C, Bouvard D, Stanchi F, Sakai T, Fassler R. Integrins in Invasive Growth. J Clin Invest (2002) 109:999-1006. doi: 10.1172/JCI0215468

57. Cai X, Thinn AMM, Wang Z, Shan H, Zhu J. The Importance of NGlycosylation on Beta3 Integrin Ligand Binding and Conformational Regulation. Sci Rep (2017) 7:4656. doi: 10.1038/s41598-017-04844-w

58. Meng X, Cheng K, Krohkin O, Mould AP, Humphries MJ, Ens W, et al. Evidence for the Presence of a Low-Mass Beta1 Integrin on the Cell Surface. Cell Sci (2005) 118(Pt 17):4009-16. doi: 10.1242/jcs.02520

59. Bazzoni G, Shih DT, Buck CA, Hemler ME. Monoclonal Antibody 9EG7 Defines A Novel Beta 1 Integrin Epitope Induced by Soluble Ligand and Manganese, But Inhibited by Calcium. J Biol Chem (1995) 270(43):25570-7. doi: $10.1074 /$ jbc. 270.43 .25570

60. Bartik P, Maglott A, Entlicher G, Vestweber D, Takeda K, Martin S, et al. Detection of a Hypersialylated Betal Integrin Endogenously Expressed in the Human Astrocytoma Cell Line A172. Int J Oncol (2008) 32(5):1021-31. doi: 10.3892/ijo.32.5.1021

Conflict of Interest: The authors declare that the research was conducted in the absence of any commercial or financial relationships that could be construed as a potential conflict of interest.

Publisher's Note: All claims expressed in this article are solely those of the authors and do not necessarily represent those of their affiliated organizations, or those of the publisher, the editors and the reviewers. Any product that may be evaluated in this article, or claim that may be made by its manufacturer, is not guaranteed or endorsed by the publisher.

Copyright $\odot 2022$ Roblek, Bicher, van Gogh, György, Seeböck, Szulc, Damme, Olczak, Borsig and Siekhaus. This is an open-access article distributed under the terms of the Creative Commons Attribution License (CC BY). The use, distribution or reproduction in other forums is permitted, provided the original author(s) and the copyright owner(s) are credited and that the original publication in this journal is cited, in accordance with accepted academic practice. No use, distribution or reproduction is permitted which does not comply with these terms. 